\title{
Trabajo de revisión: melanoma
}

\author{
CASARIEGO ZJ* \\ BAUDO JE**
}

Casariego ZJ, Baudo JE. Trabajo de revisión: melanoma. Av Periodon Implantol. 2004; 16, 3: 157-177.

\begin{abstract}
RESUMEN
El melanoma maligno es derivado de células dendríticas (névicas) proliferantes progenitoras de lesiones. Son importantes en la histogénesis y en el riesgo de desarrollo del melanoma maligno.
\end{abstract}

Del 30\% al 37\% de los melanomas malignos del tracto aero-digestivo superior están asociados a una lesión premaligna melanótica.

Los hallazgos histopatológicos con técnicas convencionales concuerdan en considerar de valor el tamaño del tumor, las células atípicas, la distribución de las células y los márgenes de la lesión.

Avances mayores en inmunología de los tumores, llevan a identificar la interacción célula tumoral - célula T.

Han sido identificados y caracterizados molecularmente un número de melanomas asociados a antígenos.

\section{PALABRAS CLAVE}

Melanoma. Nevos. Diagnóstico Precoz. Inmunología. Angiogénesis. Metástasis.

Aceptado para publicación: Mayo 2004

\section{INTRODUCCIÓN}

La cavidad bucal es una localización poco frecuente para el desarrollo de un melanoma maligno primario, por el contrario, en la piel tiene alta prevalencia y aumenta su incidencia año a año. El odontólogo desarrolla su actividad clínica en un área que le permite la visualización directa de la piel de la cara y el cuello, de allí la importancia del conocimiento de las características clínicas de esta neoplasia. Puede sospecharse de un melanoma, con un simple examen clínico de una lesión pigmentaria, posibilitando la extirpación de la lesión en un estadio precoz con un pronóstico muy bueno, sin embargo, cuando el melanoma se reconoce en un estadio avanzado el pronóstico es mucho más sombrío.

\section{EPIDEMIOLOGÍA}

El melanoma es un tumor maligno derivado de los melanocitos y las células névicas. Se puede presentar en piel, mucosa, en toda región anatómica que presente melanocitos: cavidad bucal, ojo, ano, o genitales. Puede originarse de nevus previos en el $50 \%$ de los casos, o en forma espontánea. Su incidencia es creciente en las últimas décadas, representa el 1,5\% $7 \%$ de las neoplasias cutáneas, pero causa el $60 \%$ $70 \%$ de las muertes por cáncer de piel; y el $1 \%-2 \%$ de las muertes por cáncer ${ }^{(1)}$.

El melanoma de la cavidad bucal es una entidad poco frecuente, variando su incidencia entre el 0,1 y el $8 \%$ de todos los melanomas, correspondiendo al 0,073\% 
de todos los tumores malignos ${ }^{(2,3,4,5,6,7)}$. Son más comunes en Uganda ${ }^{(8,9)}$ y Japón (7,5\% de los melanomas del organismo, o el $34,4 \%$ de todos los melanomas mucosos según Takagi et al. ${ }^{(10)} ;-12,4 \%$, según Tanaka et al. $\left.{ }^{(11)}\right)$.

\section{LOS FACTORES DE RIESGO DEL MELANOMA CUTÁNEO}

\author{
$\checkmark$ Radiación solar \\ $\checkmark$ Fenotipo cutáneo \\ $\checkmark$ Situación geográfica \\ $\checkmark$ Presencia de nevos \\ $\checkmark$ Herencia \\ $\checkmark$ Hormonas y embarazo \\ $\checkmark$ Inmunosupresión \\ $\checkmark$ Edad \\ $\checkmark$ Sexo
}

\section{RADIACIÓN SOLAR}

Nuestro planeta es bombardeado constantemente por radiación electromagnética emanada principalmente del sol. Aunque la atmósfera terrestre actúa como un filtro de esta radiación, una cantidad importante llega a su superficie y por consiguiente a nosotros. Desde el punto de vista biológico, los fotones asociados con longitudes de onda más cortas que las visibles son de gran importancia. Esta radiación de una longitud de onda más corta que la de color violeta recibe el nombre de ultravioleta (UV), cubre un rango entre 200 y 400 nanómetros, es invisible y sólo puede ser detectada con instrumentos adecuados o por sus efectos biológicos.

La radiación de onda más corta (entre 200 y $290 \mathrm{~nm}$ ) es llamada UVC y es la más activa biológicamente: es altamente cancerígena y bactericida pero es filtrada por completo por la capa de ozono en la atmósfera superior. La radiación UVB (entre 290 y $320 \mathrm{~nm}$ ) es también cancerígena y produce quemadura solar aguda. Este tipo de radiación es parcialmente filtrada por la capa de ozono y puede ser totalmente absorbida por los protectores solares convencionales. La radiación UVB nos llega en cantidades importantes y puede penetrar hasta la capa basal de la epidermis. Allí puede inducir alteraciones cancerígenas en las células y es por lo tanto responsable del carcinoma basocelular.

Los rayos UVA comprenden la radiación de longitud de onda más larga (320 a $400 \mathrm{~nm}$ ) y son los principa- les responsables del bronceado solar. Aunque se sabe que pueden producir envejecimiento prematuro de la piel, hasta no hace mucho tiempo se pensaba que no eran cancerígenos. Sin embargo, estudios recientes en animales han demostrado su potencial cancerígeno y sus efectos sobre el sistema inmunológico de la piel. Es importante notar que esta radiación no es filtrada por la capa de ozono, sus efectos son más insidiosos ya que no producen reacciones agudas como los UVB y penetran más profundamente en la piel. En la dermis pueden despolimerizar el colágeno, afectar la actividad de los fibroblastos e inducir elastosis y cambios que percibimos como "arrugas". Se ha demostrado que estos rayos pueden afectar células específicas de la piel relacionadas con nuestro sistema inmunológico (las células de Langerhans) a quienes la literatura actual involucra en la iniciación del melanoma maligno.

Aunque la actividad biológica de la radiación UVA es mucho más débil que la del UVB, la radiación solar contiene aproximadamente mil veces más UVA que UVB. Es interesante también notar que la luz fluorescente emite una cantidad pequeña pero tal vez biológicamente significativa de UVA.

Los protectores solares convencionales son muy efectivos en la protección contra los rayos UVB y bien formulados pueden proveer factores de protección solar de 20 o más. Estos productos permiten al usuario permanecer al sol prácticamente el día entero sin sufrir el daño agudo por quemadura solar. Sin embargo, para obtener un factor de protección solar 20 sólo hay que absorber el $95 \%$ del UVB y muy poco del UVA. Por lo tanto, mientras el usuario de estos productos está expuesto al sol todo el día sin quemarse, su piel continúa siendo bombardeada por los UVA presentes en gran proporción en la radiación solar y, además, por la pequeña cantidad de UVB que el producto deja pasar.

Es evidente que cuanto más oscuro el color de la piel, tanto más baja es la incidencia de cáncer de piel. La melanina, el pigmento que provee el color a nuestra piel, nos protege contra la radiación solar; por lo tanto, la síntesis de melanina puede ser considerada un mecanismo para la supervivencia. La enzima clave para la producción de la melanina, a partir del aminoácido tirosina, es la tirosinasa.

La melanina es producida genéticamente como reacción a la exposición al sol en células especializadas: los melanocitos.

Mientras que los protectores solares convencionales sólo actúan absorbiendo radiación solar de una longitud de onda especificada, la melanina exhibe una multiplicidad de acción fotoprotectora. No sólo absor- 
be radiación ultravioleta y la visible del espectro solar actuando como un filtro neutro, sino que puede también dispersar la radiación incidente a través de los fotones ultravioleta y, hacerles perder su energía intrínseca. En la epidermis de un individuo de raza negra, los melanosomas forman partículas discretas que contribuyen a aumentar la eficacia protectora para el UV ya que no sólo absorben la radiación sino también la dispersan eficientemente dado que tienen el tamaño óptimo para interferir con la penetración de los rayos UVA.

Es sabido que la melanina puede actuar como una trampa para electrones inestables, ya que tiene la propiedad de formar radicales libres sumamente estables. De esta manera, la melanina previene la formación de radicales libres inestables que pueden dañar los componentes celulares y que constituyen uno de los mecanismos principales de iniciación de cáncer ${ }^{(12 .}$ $13,14,18,16,17,18)$.

\section{FOTOTIPO}

El fototipo (FT), considerado como reacción o respuesta de la piel al sol, también ha sido evaluado como factor de riesgo en el melanoma. Se ha observado que los pacientes con melanoma presentan una dosis mínima de eritema inferior a los individuos sanos, y una tendencia a que este eritema sea más prolongado tras la exposición a la radiación UV. En diversos estudios de casos y controles se ha comprobado que los sujetos que se queman fácilmente y se broncean con dificultad están expuestos a un riesgo mayor de melanoma ${ }^{(19,20,21,22,23,24)}$.

Cuando se considera la sensibilidad al sol o FT es necesario controlar la exposición solar, debido que ambos factores se correlacionan negativamente (los individuos con FT bajos tienden a exponerse menos al sol, y viceversa). Por ello, es posible que el riesgo real debido a la sensibilidad al sol sea mayor que los obtenidos en la mayoría de los estudios ${ }^{(25)}$.

\section{SITUACIÓN GEOGRÁFICA}

La observación epidemiológica de la incidencia del cáncer de piel en distintas poblaciones provee una información sumamente interesante. Cerca de las costas de Panamá en las islas de San Blas, viven los indios de la tribu Cuna. Los nativos de una de estas islas son genéticamente albinos y se observa que todos ellos desarrollan neoplasias cutáneas malignas antes de llegar a los 30 años. Por otro lado, en Australia se ha establecido que más del $80 \%$ de la población anglo sajona desarrolla algunas de las formas de cáncer de piel antes de llegar a los 50 años y en los Estados
Unidos, se calcula que el $50 \%$ de la población de más de 50 años desarrollará neoplasias cancerizables. Sin embargo, en la India donde la exposición al sol es mucho más intensa, no más del $1 \%$ de la población eventualmente presenta algunos de estos cuadros. Finalmente, en el Africa, una de las zonas del planeta más intensamente expuesta a la radiación ultravioleta, los nativos raramente presentan alguna alteración relacionada excepto en las áreas no pigmentadas del cuerpo como la palma de las manos o las plantas de los pies o, si sufren de vitiligo, en las zonas ausentes de pigmento ${ }^{(26,27)}$.

\section{PRESENCIA DE NEVOS}

La presencia de eférides (pecas) o la tendencia a su desarrollo, se ha asociado con un aumento del riesgo al melanoma, apareciendo en algunos estudios como el segundo factor de riesgo más importante para desarrollo de melanoma en mujeres y el tercero en varones $^{(28,29)}$.

El melanoma es precedido por algunas lesiones melanocíticas proliferativas o lesiones pigmentarias elevadas. De esta manera, la forma de la lesión precursora del melanoma es importante en la histiogénesis del melanoma maligno, e importante en la determinación del riesgo para desarrollar melanoma maligno en algunos pacientes.

Las lesiones precursora puede clasificarse en dos grandes grupos: las que tienen una tendencia regresiva y las que tienen una tendencia progresiva. Dentro de las primeras encontramos al nevo común. 303132 333435

\section{HERENCIA}

Existe un síndrome familiar en el que el riesgo de desarrollar melanomas está muy aumentado. Este síndrome de melanoma familiar explicaría el 10\% del total de melanomas diagnosticados. Se trata de un síndrome hereditario, con un modo de transmisión dominante y una penetrancia incompleta. Los melanomas que se presentan en estas personas aparecen en edades más precoces.

El estudio citogenético de los melanomas, principalmente metastásicos, ha detectado alteraciones en los cromosomas $^{(1,6,7,9,10 \text { y } 11)}$, tanto en la forma esporádica como la familiar ${ }^{(1)}$.

\section{HORMONAS Y EMBARAZO}

Los factores hormonales no parecen influir en la inci- 
dencia del melanoma, similar para ambos sexos, aunque algunos datos sugieren que pueden desempeñar un papel en la etiopatogenia. En ocasiones se ha observado que los melanomas desarrollados durante el embarazo pueden regresar al término de la gestación

Diversos trabajos han detectado mayor supervivencia en mujeres que en varones, independientemente del estado evolutivo. También se ha señalado que esta supervivencia más prolongada no es aplicable a mujeres post - menopáusicas o mayores de 50 años.

En algunos estudios epidemiológicos se ha observado un aumento del riesgo de melanoma asociado al uso de anticonceptivos orales ${ }^{(30,36,37,38,39,40,41,42,43)}$.

\section{INMUNOSUPRESIÓN}

La existencia de una respuesta inmune del huésped frente al tumor se pone de manifiesto por diversos hechos clínicos, histológicos, inmunológicos y terapéuticos. Se ha asociado un estado inmunitario deficiente a un incremento en la incidencia de varios tipos de neoplasias, incluidos el carcinoma a células escamosas, el linfoma y el melanoma, observándose una incidencia mayor de la esperada de melanoma en pacientes sometidos a trasplante renal. También se ha comunicado una incidencia de melanoma 8 veces superior a lo esperado en pacientes tratados por enfermedad de Hodgkin y de más del doble en enfermos con linfoma no Hodgkin ${ }^{(30)}$.

\section{SEXOY EDAD}

La incidencia es similar en ambos sexos, aunque el pronóstico es mejor en las mujeres. La edad media de los pacientes en el momento del diagnóstico es de 45 años. La incidencia de la enfermedad aumenta con la edad $^{(1)}$.

\section{TRANSFORMACIÓN}

La transición de un organismo sano a un estado de cáncer puede suceder de una o dos maneras: 1- La transmisión hereditaria en estado de cigoto o, 2- La alteración del organismo o una alteración de un tejido o un órgano dentro del organismo en la vida postcigota, durante la vida embrionaria o en la vida extrauterina. Estos dos mecanismos, hereditario y adquirido, que condicionan un estado para el cáncer, no pueden ser separados completamente, el cáncer resulta de la interacción de ambos en distintas proporciones. $\mathrm{El}$ estado de precursor es un estado de susceptibili- dad al desarrollo de una lesión precursora que puede transformarse en cáncer ${ }^{(44,45,46)}$.

\section{MELANOMA IN SITU}

En 1987, Elder y Clark, escribieron en "Patobiología del melanoma maligno": El melanoma in situ es una lesión confinada en la epidermis, pero se considera la misma neoplasia maligna en base a que la citología y el cuadro histológico es similar a la del melanoma totalmente desarrollado.

La identificación del melanoma cuando aún está in situ, permite la eliminación completa de la lesión, por tanto la prevención de posteriores metástasis y la muerte por melanoma. Estos pacientes deben ser seguidos cuidadosamente debido a que tienen mayor riesgo de desarrollar un melanoma secundario. El rango de hallazgos de melanoma in situ por microscopía convencional es extraordinario, desde un número aumentado de melanocitos aparentemente típicos como unidades solitarias dispuestos a lo largo de la unión dermo - epidermal, hasta melanocitos notablemente atípicos dispuestos como unidades solitarias o en nidos que se esparcen a lo largo de la epidermis y la estructura epitelial continua. Las células presentan un citoplasma abundante con algunos gránulos finos de melanina. El núcleo puede no presentarse hipercromático. El nucleolo es visible a veces prominente. $\mathrm{El}$ estroma subyacente puede mostrar focos de fibro$\operatorname{plasia}^{(47,48,49,50,51,52) \text {. }}$

El melanoma in situ es una fase de la progresión tumoral del melanoma, con células con características citológicas de malignidad pero confinadas en el epitelio. El melanoma in situ, junto con el melanoma microinvasivo, constituye la fase de crecimiento radial en la tumorogenisis del melanoma. La fase de crecimiento radial del melanoma es importante biológicamente ya que representa la falta de metástasis precursora de la fase de crecimiento vertical (tumorogénesis) enfermedad que se desarrolla inexorablemente en un alto porcentaje de las lesiones no tratadas. El melanoma in situ puede persistir por un largo período de tiempo antes de desarrollar un crecimiento vertical, esto representa un importante objetivo para un reconocimiento clínico e histopatológico para el éxito terapéutico y la cura del paciente.

El melanoma in situ está generalmente compuesto por una extensa proliferación intraepidérmica de melanocitos atípicos acompañado a menudo por una hiperplasia epitelial asimétrica o a veces atrofia. En el examen del melanoma se aprecia un aumento de células epiteloides claras, fusiformes y poliédricas. Estas 
células definen el tejido enfermo, se presentan a lo largo o como nidos coalescentes; simple crecimiento de células pagetoides a nivel de la epidermis; y proliferativas en la serie lentiginosa; resultando en un reemplazo continuo de las células de la capa basal. Las células pagetoides de algunos nevos envuelven el estrato granuloso y el estrato córneo pero son de aspecto más típico que las del melanoma in situ. Citológicamente la atipía del melanoma in situ tiende a ser uniforme. Consiste en agrandamiento nuclear, membrana nuclear irregular y engrosada, heterocromatina agrupada groseramente que resulta ocasionalmente en una hipercromasia, y a veces nucléolos prominentes. El citoplasma presenta gránulos de melanina. Es frecuente observar actividad mitótica y necrosis.

El melanoma in situ es una lesión de historia natural incierta, pero puede ser tratado efectivamente con cirugía convencional. Una vez que la lesión ha sido totalmente removida, el melanoma in situ no debe provocar un impacto en la longevidad del paciente.

El diagnóstico de melanoma in situ (displasia melanocítica severa, lesión melanocítica atípica), debe dejar 2 mensajes importantes al clínico: 1-se cura luego de una excisión completa con margen de seguridad, y 2aumenta el riesgo de desarrollar un melanoma secundario, por lo cual es necesario realizar un estudio completo de la piel anualmente ${ }^{(53,54,56,56,57,58,59)}$.

\section{MELANOMA MALIGNO}

\section{CLASIFICACIÓN:}

\author{
$\checkmark$ Melanoma de extensión superficial \\ $\checkmark$ Melanoma nodular \\ $\checkmark$ Melanoma lentigo maligno \\ $\checkmark$ Melanoma lentiginoso acral
}

El melanoma de extensión superficial es el tipo más frecuente de melanoma maligno, 70\% de los casos. Afecta a personas entre la cuarta y quinta décadas de vida, se localiza preferentemente en extremidades inferiores y en el tronco de las mujeres, y en el tronco de los varones, áreas de exposición solar intermitente pero intensa. Se origina como una lesión pequeña de color marrón negruzco a veces con decoloración focal azulada, aumenta de tamaño centrífugamente (crecimiento radial), presentando un espectro de colores del rojo, al blanco o azul negruzco. La fase de crecimiento vertical, invasiva, se traduce clínicamente por la aparición de un nódulo, y ocurre generalmente al alcanzar un diámetro de $2,5 \mathrm{~cm}$, después de meses o años de evolución.
El melanoma nodular reúne alrededor del 15\% de los casos. Se presenta entre la quinta y sexta década de vida, con preferencia en extremidades inferiores y tronco. En principio es una lesión azul negruzco que puede confundirse con un hematoma o un hemoangioma. Posteriormente crece de forma rápida (fase de crecimiento vertical) hasta formar una lesión nodular de color homogéneo azul negruzco, violáceo o rojo amarronado, que puede ulcerarse, esta úlcera es sangrante, blanda y con bordes cortados a pico. Invade los vasos sanguíneos y los vasos linfáticos, por los cuales se disemina a distancia, pudiendo metastatizar en cualquier órgano de la economía. Dentro de este tipo de melanoma existe la variedad amelanótica que representa un importante problema diagnóstico debido a la ausencia de pigmento. Se observa como un nódulo eritematoso, rosado o del color de la piel. El melanoma lentigo maligno representa un $5 \%$ y suele originarse sobre una lesión precursora, el lentigo maligno, de 5 a 50 años de evolución. Afecta a pacientes de edad avanzada, se localiza en áreas expuestas que muestran daño actínico como la cara, el cuello, extensión de los antebrazos y las manos, localización de exposición solar acumulada.

Se observa como una mácula con distintos tonos de marrón oscuro, negro o azul. El crecimiento radial finalmente se convierte en crecimiento vertical con la aparición de un nódulo sobreelevado.

El 10\% de los melanomas malignos corresponden al lentiginoso acral. En razas negra y orientales se encuentra con una incidencia muy superior a la de la raza caucásica. Se presenta como una mácula hiperpigmentada de bordes irregulares y variación de color, habitualmente negro o azul. Eventualmente puede desarrollar un componente nodular, ulcerarse y sangrar cuando existe invasión de los planos profundos. Se localiza en planta y palmas, en el lecho ungueal y en las mucosas. Los melanomas subungueales pueden presentarse en forma de una estriación pigmentada irregular con desbordamiento del pigmento en el pliegue proximal de la uña (signo de Hutchinson) ${ }^{(60,61,62,63,64,65,66,67)}$.

Melanoma bucal: para considerar un melanoma como primario de la cavidad bucal deben tenerse en cuenta tres criterios:

\section{$\checkmark$ Demostración tanto clínica como histológica del melanoma maligno. \\ $\checkmark$ Presencia de actividad intraepidérmica. \\ $\checkmark$ Imposibilidad de demostrar otro lugar primario.}

Aparece entre la $6^{\mathrm{a}}$ y $7^{\mathrm{a}}$ década de la vida, a una edad algo superior a la común en los melanomas cutáneos. La edad media ronda los 68 años ${ }^{(68)}$, apareciendo el $82 \%$ de ellos por encima de los 40 años ${ }^{(69)}$. Pese a no 
observarse por lo común ninguna predilección sexual $^{(8)}$, no faltan referencias reconocedoras de un mayor predominio en los varones (58\%, para Rapini ${ }^{(69)}$; y 1,7: 1 para Bucci $\left.^{(70)}\right)$.

Los melanomas del tracto aerodigestivo superior se asocian en un $30-37 \%$ de las ocasiones a melanosis preexistentes $^{(9,69)}$.

El melanoma bucal tiene una presentación variable, pudiendo hacerlo de forma repentina y con un crecimiento rápido provocando ulceración, hemorragia y dolor; si bien estos síntomas son raros en los estadios iniciales de la enfermedad y con frecuencia únicamente se aprecia un paulatino aumento de tamaño, con pérdida de dientes por la destrucción ósea o desajustes en la prótesis removible ${ }^{(8,69)}$. También cabe la posibilidad de que se trate de una lesión metastásica, en cuyo caso suele expresarse como un nódulo liso blanco o azulado cubierto por una mucosa intacta, siendo menos frecuente el sangrado ${ }^{(71)}$.

Por su localización, el diagnóstico debería ser precoz, pero lo cierto es que es tardío y el porcentaje de supervivencia muy escaso, posiblemente por la indefinición en los síntomas, al menos en los estadios iniciales y en segundo lugar por la dificultad en el tratamiento quirúrgico debido a la anatomía del área afectada, así como por la edad de los pacientes.

Aunque puede asentar en la encía mandibular, mucosa yugal, lengua y labio, la localización más frecuente es en el complejo paladar - mucosa alveolar ${ }^{(10)}$; como explicación se han implicado traumatismos repetidos por las prótesis, factores químicos (tabaco y alcohol) y la pobre higiene bucal, pero son factores muy controvertidos. En cambio, es más aceptada la importancia de la existencia previa de máculas pigmentadas asintomáticas que pueden existir desde la infancia o la pubertad.

No se puede realizar una clasificación del melanoma bucal como la que se da en el melanoma cutáneo, ya que son biológicamente diferentes. Los criterios de Clark son inaplicables por la peculiar histología de la mucosa bucal. La clasificación histológica parece ser la más correcta: in situ, con un patrón de creci- miento radial, e invasivo, con un patrón de crecimiento vertical. El diagnóstico diferencial debe realizarse con: mácula melanótica, melanosis asociada al tabaco, nevus, tatuaje por amalgama y sarcoma de Kaposi.

Una lesión pigmentada bucal que no sea clínicamente diagnosticada en forma evidente, debe ser biopsiada rápidamente ${ }^{(2)}$.

El melanoma ocular se origina en la coroides y el cuerpo ciliar. Se ha observado que la extirpación quirúrgica del globo ocular afectado puede facilitar la diseminación de la enfermedad, en forma de micrometástasis clínicamente indetectables, que pueden permanecer en silencio durante años hasta que progresan y son diagnosticadas. Las metástasis hepáticas son una forma frecuente de recidiva de melanoma ocular, dando lugar al síndrome de hepatomegalia, ictericia y ojo de cristal.

En las mujeres el melanoma vulvar representa el 5\% al $10 \%$ de las neoplasias malignas de la vulva ${ }^{(72)}$.

\section{ABC DEL MELANOMA CUTÁNEO (TABLA 1)}

Toda lesión cutánea preexistente o de novo es susceptible de biopsia si presenta alguna de las siguientes características, que se consideran el ABC clínico de sospecha de melanoma ${ }^{(73)}$ :
A. Asimetría
B. Borde irregular
C. Variaciones en color
D. Diámetro de al menos $6 \mathrm{~mm}$
E. Elevación sobre la superficie cutánea

\section{HISTOPATOLOGÍA}

Los criterios histopatológicos con técnicas convencionales consideran en la valoración del melanoma los aspectos de tamaño tumoral, atipía, distribución celular y márgenes de la lesión. (Tabla 2).

\begin{tabular}{|l|l|}
\hline \multicolumn{2}{|c|}{ TABIA 1.- CRITERIO DE SOSPECHA DE MELANOMA } \\
\hline OBSERVACión & \multicolumn{1}{|c|}{ SOSPECHA DE MALANOMA } \\
\hline Color de la lesión & Lesión marrón o negra con variación de color rojo, rosa, gris, blanco o azul \\
\hline Configuración & Bordes irregulares, asimetría \\
\hline Topografía & Superficie irregular \\
\hline Despigmentación & Sugiere destrucción inmunológica de melanocitos o células de melanoma \\
\hline
\end{tabular}




\begin{tabular}{|c|c|}
\hline \multicolumn{2}{|c|}{ TABLA 2.- CRITERIOS DIAGNÓSTICOS HISTOPATOLÓGICOS } \\
\hline MELANOMA INTRAEPIDÉRMICO O MICROINVASIVO & MELANOMA INVASIVO CON NÓDULOS O PLACAS DÉRMICAS \\
\hline $\begin{array}{l}\text { Arquitectura: } \\
\text { Tamaño generalmente > } 4-5 \mathrm{~mm} \text {. } \\
\text { Asimetría de la arquitectura en general } \\
\text { Márgenes mal definidos } \\
\text { Pérdida de la arquitectura névica }\end{array}$ & $\begin{array}{l}\text { Arquitectura: } \\
\text { Expansión de nódulos o placas en dermis papilar } \\
\text { Infiltración difusa de dermis reticular } \\
\text { Infiltración de grasa subcutánea }\end{array}$ \\
\hline $\begin{array}{l}\text { Citología: atipía uniforme en la población celular, } \\
\text { células grandes, núcleos grandes, pleomórficos, } \\
\text { hipercromáticos con nucleolos evidentes }\end{array}$ & $\begin{array}{l}\text { Citología: grandes atipías, frecuente pérdida de } \\
\text { síntesis pigmentaria }\end{array}$ \\
\hline
\end{tabular}

En los cuatro tipos de melanoma maligno, el tumor casi siempre se origina en la unión de la epidermis con la dermis. Las células tumorales poseen núcleos anaplásicos y es común que asciendan hacia la epidermis superficial, esto sucede en el lentigo maligno y el lentiginoso acral. Las células del melanoma varían de tamaño y forma pero se parecen a las epiteloides o las basales o fusiformes. Las epiteloides son las más comunes y se disponen rodeando cavidades tipo alvéolos, en cambio las fusiformes dan ramificaciones irregulares.

La cantidad de melanina es muy variable. En algunas lesiones no sólo se ubica en las células tumorales sino también en el estroma. La magnitud del infiltrado también es disímil. En general en el melanoma maligno invasor reciente se observa un infiltrado inflamatorio en bandas, a menudo entremezclado con melanófagos situados debajo del tumor. En los tumores que invaden la dermis el infiltrado se extiende hasta la epidermis.

El espesor del tumor es el factor aislado más importante para realizar un pronóstico de sobrevida del paciente $^{(72)}$.

\section{NIVELES DE RIESGO}

La profundidad de la invasión se determina por 5 niveles propuestos por Clark y son:

$\checkmark$ Nivel I: células tumorales confinadas a la epidermis y sus anexos.

$\checkmark$ Nivel II: extensión a la dermis papilar, con muy pocas células de melanoma en la interfase entre la dermis papilar y reticular.

$\checkmark$ Nivel III: extensión a la dermis papilar ocupándola y dirigiéndose a la reticular pero sin invadirla.

$\checkmark$ Nivel IV: invasión de la dermis reticular.
Nivel V: invasión del tejido celular subcutáneo.

Otra clasificación para recordar es la de Breslow:

$\checkmark$ Bajo riesgo: melanomas de menos de 0,76 mm de espesor y nivel II o III.

$\checkmark$ Riesgo moderado: a) melanomas de menos de 0,76 $\mathrm{mm}$ y nivel IV; b) melanomas entre 0,76 y $1,5 \mathrm{~mm}$; y c) melanomas de más de $1,5 \mathrm{~mm}$ y nivel III.

$\checkmark$ Alto riesgo: melanomas de más de 1,5 mm de espesor y nivel IV o V.

La incidencia de compromiso de los ganglios linfáticos regionales aumenta con el espesor del tumor. La cantidad de ganglios linfáticos involucrados y la profundidad del tumor son factores pronóstico. La diseminación por vía sanguínea ocurre más tarde y las metástasis suelen ser múltiples, en orden de frecuencia en piel, pulmón, hígado, cerebro, hueso e intestino ${ }^{(2)}$.

\section{CLASIFICACIÓN TNMI}

La extensión del tumor (T) se clasifica después de su excisión y se relaciona con los niveles de Clark:

Tis $=$ Nivel I

T1 = Nivel II

T2 = Nivel III

T3 = Nivel IV

T4 = Nivel V

Ganglios linfáticos regionales (N)

Nx: No se pueden evaluar

N0: No se demuestran metástasis ganglionares regionales

N1: Metástasis de diámetro máximo menor a $3 \mathrm{~cm}$ en cualquier ganglio regional (Fig. 1).

N2: Metástasis de diámetro mayor a $3 \mathrm{~cm}$ en cualquier ganglio regional y/o metástasis en tránsito (son las que afectan a la piel o al tejido celular subcutáneo a 
una distancia superior a $2 \mathrm{~cm}$ desde el tumor primario, pero no más allá de los ganglios regionales) (Fig. 2).

N2a: Metástasis de diámetro máximo mayor de $3 \mathrm{~cm}$ en cualquier ganglio regional.

N2b: Metástasis en tránsito.

N2c: Ambas.

Metástasis a distancia (M)

Mx: No se puede evaluar las metástasis a distancia.

M0: No existen metástasis a distancia.

Mla: Metástasis en la piel o tejido celular subcutáneo o en ganglios linfáticos más allá de los regionales.

Mlb: Metástasis visceral.

\section{Etapas clínicas:}

IA: Tl N0 M0

IB: T2 NO MO

IIA: T3 NO MO

IIB: T4 NO MO

III: cualquier T N1 M0

IV: cualquier T, cualquier $\mathrm{N}, \mathrm{Ml} .72$

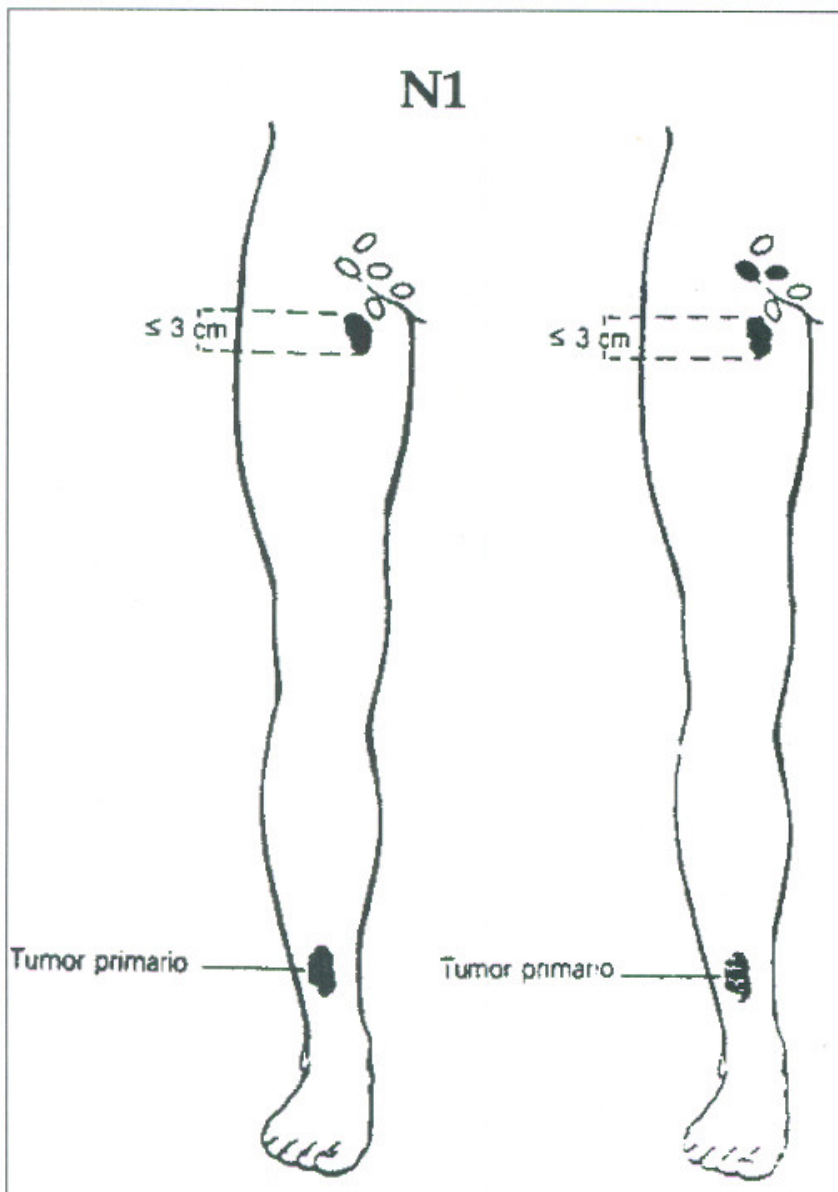

Fig. 1
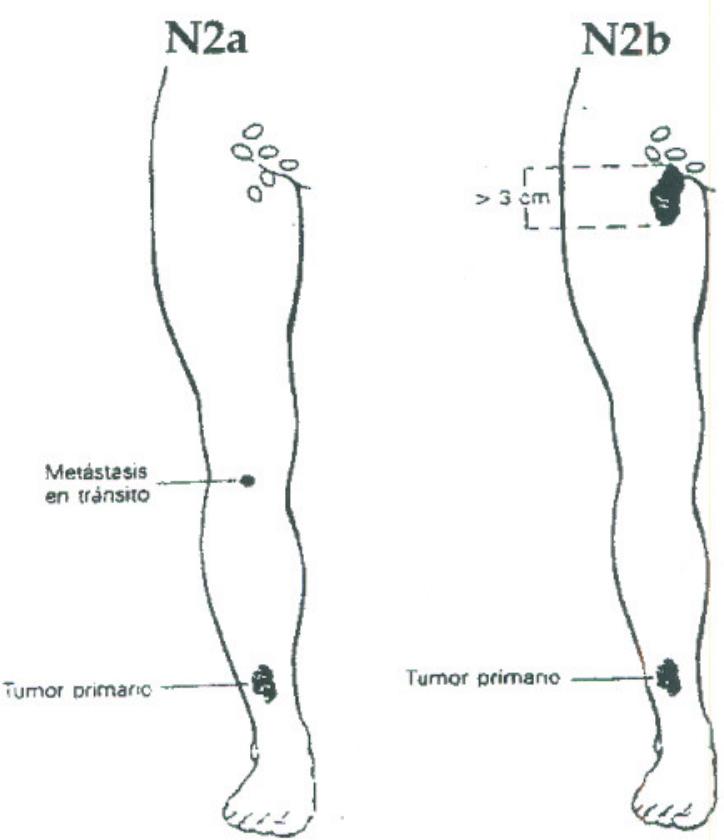

Fig. 2

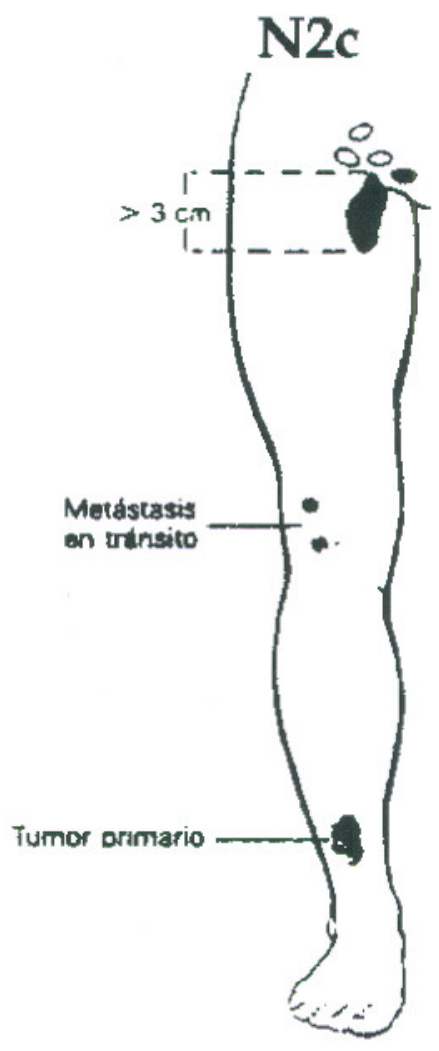




\section{LESIONES SIMULADORASS DE MELANOMA}

\section{SIMULADORES CLÍNICOS SEGÚN LA MORFOLOGÍA DE LA LESIÓN}

Lentigo simple: Mácula pigmentada marrón oscuro o negra, bien delimitada. Se presenta preferentemente en la infancia sin predisposición por zonas expuestas. Mide menos de $1 \mathrm{~cm}$, eventualmente puede evolucionar a un nevo de unión ${ }^{(74)}$.

Lentigos solares: Se observan en áreas expuestas, en personas de edad avanzada. Son máculas irregulares, marrón oscuras y de pigmentación homogénea, hasta $1 \mathrm{~cm}$ de diámetro ${ }^{(75)}$.

Nevo melanocítico adquirido: La presencia de nevos melanocíticos comunes adquiridos en la población se estima en el $100 \%$, pudiendo afirmarse que todos los individuos poseen algún nevo de este tipo, con un promedio de 15 a 30 al final de la segunda década de la vida. Poseer un gran número de nevos se considera un factor de riesgo elevado, y algunos autores lo consideran el factor de riesgo personal más importante para el desarrollar un melanoma, aún en la edad infantil.

La exposición solar desempeña un papel importante en la formación de los nevos, ya que el número máximo de nevos en áreas anatómicas fotoexpuestas se alcanza antes y es mayor que en las zonas cubiertas. La cantidad total de nevos mantiene relación con el fototipo y con la exposición solar en la infancia y en la adolescencia, influyendo notablemente el número de quemaduras solares en la infancia.

Nevos y melanomas se desarrollan en individuos con melanocitos genéticamente susceptibles sobre los que actúan estímulos ambientales, y de los que la radiación UV es el más importante. El nevo de unión se observa en los niños y adultos jóvenes como una mácula pigmentada marrón claro u oscuro, simétrica y circunscrita, menor a $1 \mathrm{~cm}$ de diámetro. Los nevos compuestos son lesiones palpables, circunscritas, hiperpigmentadas y de bordes bien definidos. Los nevos intradérmicos son pápulas del mismo color de la piel por la profundidad del pigmento ${ }^{(76)}$.

Nevo melanocítico congénito: Los nevos congénitos presentan un riesgo elevado para el desarrollo de melanoma cutáneo y extracutáneo. El riesgo parece ser mayor en los nevos de localización axial que en los de las extremidades.

Las melanocitosis dérmicas son formaciones névicas marrón o azul presentes al nacimiento o manifestadas algún tiempo más tarde. Bajo esta denominación se agrupan las siguientes entidades: mancha mogólica, nevo azul, nevo de Ito y nevo de Ota. La mancha mogólica es una mácula azul grisácea de ubicación lumbo sacra o en otro lugar del tronco que desaparece en los primeros años de vida. Se presentan desde el nacimiento, según su tamaño pueden ser gigantes o no gigantes. De tamaño generalmente mayor a los adquiridos, son simétricos, bien delimitados y de coloración uniforme. El nevo azul es de pigmentación cutánea negro azulada, de bordes irregulares o discontinuos, con localización frecuente en las extremidades, las nalgas y la cara. El nevo de Ito es de pigmentación azulada acromio - clavículo - deltoidea. El nevo de Ota es una lesión facial unilateral integrada por máculas azules y pardas que confluyen, afectando la región periorbitaria, la sien, la frente, la zona malar y/o la nariz. Se acompaña generalmente de una pigmentación mucosa: ocular, palatina, nasofaríngea y timpánica. El 50\% aparece en menores de un año. De etiología incierta, el área facial comprometida y su naturaleza congénita, sugiere una anomalía en el desarrollo de la cresta neural. Histológicamente revela en la dermis melanocitos dendríticos y alargados dispersos entre los haces colágenos. Aunque la mayoría se localiza en el tercio superior de la dermis reticular, en algunas lesiones también se identifican en la zona papilar y en otras alcanzan el tejido subcutáneo. Como la concentración de melanocitos en el nevo de Ota es mayor que en la mancha mogólica, es indudable que no representa a células névicas residuales como en ésta, sino a un hamartoma o lesión nevoide, como sucede en el nevo azul. La mancha mogólica nunca se maligniza, mientras que se han descripto casos de melanoma en pacientes con nevo de Ota. Suelen ser lesiones múltiples y de diámetro superior al del nevo adquirido, más de 5 mm ${ }^{(77,78,79,80,81,82,83,84)}$.

El nevo azul maligno es un tumor excepcional que puede originarse de un nevo azul o ser maligno desde un principio. Difiere del melanoma maligno porque histológicamente hay ausencia de actividad en la unión. Además de los signos habituales de malignidad, como el desarrollo invasor, la atipía y el pleomorfismo de los núcleos y la existencia de mitosis anormales, el nevo azul maligno muestra zonas de necrosis ${ }^{(85,86,87)}$.

Nevo displásico: Dentro de las lesiones precursoras con tendencia a progresar encontramos al nevo displásico (ND) que clínicamente se presenta como un nevo atípico con un tamaño mayor a $5 \mathrm{~mm}$. Algunas lesiones tienen un aspecto plano totalmente o sólo con algunos componentes planos. Por lo menos deben observarse dos de las siguientes 3 características: pigmentación variable, contorno asimétrico irregular, y bordes difusos.

No suelen estar presentes al nacer, se inician en la adolescencia y continúan apareciendo en la edad adulta. 
El significado del ND en términos de riesgo de transformación maligna varía según el contexto en que aparece. Por ello, se ha propuesto su clasificación en varios grupos:

1. Tipo A: individuos con múltiples ND, sin historia personal de melanoma, ni familiar de ND ni de melanoma.

2. Tipo B: individuos con ND y antecedentes familiares de ND, pero no de melanoma personal ni familiar.

3. Tipo C: individuos con ND y melanoma, sin historia familiar de ND ni de melanoma.

4. Tipo D: individuos con ND y melanoma, y antecedentes familiares de melanoma en uno o varios miembros de la familia.

Se halló que los sujetos con el síndrome del ND familiar presentan un riesgo elevado de melanoma, del $10,7 \%$ a los 10 años. Se ha registrado una asociación entre ND y melanoma en el $5-40 \%$ de casos de melanoma esporádico. El aumento del riesgo ha sido observado en estudios de Swerdlow AJ y colaboradores ${ }^{(30)}$ en los que se ha documentado las características morfológicas de estos nevos, atribuyéndoseles un aumento de riesgo 70 veces superior a los nevos con bordes irregulares y de 30 a los nevos con variaciones en el color ${ }^{(8,89,80)}$.

Halo - nevo: Se caracteriza por poseer una zona bien demarcada de despigmentación alrededor del nevo pigmentado. Las lesiones pueden ser múltiples, y se suelen localizar en el tronco de personas jóvenes. Se supone que la pérdida de pigmento es debida a una respuesta inflamatoria mediada inmunológicamente, dirigida contra la melanina o melanoma, dentro de la lesión o a distancia de ésta. A pesar de que el fenómeno del halo - nevo es un proceso benigno es imperativo, especialmente en adultos, el descartar la existencia de un posible melanoma ${ }^{(74)}$.

Nevo de Spitz: Denominado también melanoma benigno juvenil, se presenta preferentemente en la cara y extremidades de niños o adultos jóvenes. Es una pápula solitaria e hiperpigmentada o sonrosada, que mide menos de $1 \mathrm{~cm}$ de diámetro. Puede confundirse con un melanoma amelanótico, pero la edad del paciente ayuda a su correcto diagnóstico ${ }^{(91,92,93,94)}$.

Lesiones vasculares: Dentro de éstas encontramos al angioma trombosado debido a la coloración azul negruzco que toma y a sus bordes irregulares. También el hematoma subungueal puede confundirse, aunque el antecedente de traumatismo, un sangrado profuso cuando se interviene en ellos y vitropresión positiva, son signos que no dejan lugar a dudas de su origen vascular. El granuloma piógeno es una lesión solitaria, pequeña, en forma de pápula o nódulo de color rojo oscuro, friable al tacto. El sarcoma de Kaposi relacionado con el sida se presenta en forma de mácula en principio y posteriormente pápulas y nódulos eritematovioláceos, suelen ser múltiples ${ }^{(60)}$.

Lesiones fibrohistiocitarias: El dermatofibroma pigmentado se presenta en extremidades inferiores en adultos como pápula o nódulo firme, solitario, eritematoso, marronáceo, entre $4 \mathrm{~mm}$ y $1,5 \mathrm{~cm}$. Se hunde cuando se ejerce una presión bilateral de sus bordes ${ }^{(60)}$.

\section{SIMULADORES SEGÚN LA TOPOGRAFÍA}

En palmas y plantas: En estas localizaciones, diferenciar clínicamente entre melanoma incipiente y nevo melanocítico resulta en ocasiones muy difícil, por lo que no está de más recomendar la extirpación preventiva de toda lesión pigmentada mayor de $5 \mathrm{~mm}$ en estas localizaciones ${ }^{(73)}$.

Lesiones ungueales o periungueales: Los melanomas y los nevos de la matriz ungueal se manifiestan por una banda ungueal pigmentada. No hay que esperar la alteración periungueal (panadizo melánico) para sospechar el melanoma. Cuando las líneas pigmentadas son múltiples, de ancho regular, de años de evolución y de color marrón homogéneo, generalmente son de origen racial o de origen tóxico ${ }^{(74)}$.

Lesiones en mucosas: El melanoma en esta localización es de aparición infrecuente pero muy grave, y aunque son habituales las melanosis o lesiones lentiginosas en mucosas, cuando exista duda, habrá que realizar una biopsia ${ }^{(60)}$.

\section{INMUNOLOGÍA DEL MELANOIMA}

El desarrollo del melanoma maligno a partir de un precursor melanocítico benigno ha sido descripto a través de 5 fases:

1- Desarrollo a partir de un nevo con arquitectura alterada y citología atípica.

2- Proliferación irregular de melanocitos dentro de la epidermis (melanoma in situ).

3- Adquisición de la capacidad de invadir y proliferar en el tejido conectivo (melanoma invasor).

4- Desarrollo de la capacidad de dar metástasis (melanoma invasor).

5- Metástasis a distancia (melanoma metastásico) ${ }^{(95)}$.

Los anticuerpos monoclonales han permitido definir antígenos que se expresan en distinto grado en estas 
fases de progresión tumoral y distinguir distintas clases de antígenos en las células de melanoma. El análisis de líneas celulares en cultivo de melanoma ha revelado que las células de melanoma van cambiando la expresión de las moléculas de HLA durante el proceso de transformación maligna. Este cambio incluye una disminución o pérdida de antígenos de clase I y la aparición de antígenos de clase II. La pérdida de la expresión de antígenos de clase I parece ocurrir en la lesión primaria. Cuanto más agresivo es el tumor, menos expresa HLA I. La pérdida de HLA I ofrece ventajas al tumor, ya que le permite escapar a la respuesta inmune celular. Por otra parte, los HLA II son expresados con más frecuencia en las metástasis que en las lesiones primarias.

La melanotrasferrina es un antígeno presente en las células del melanoma, es una sialoglicoproteína fosforilada capaz de ligar hierro. El hecho de ser un antígeno de superficie y de expresarse significativamente más en melanoma que en tejidos normales hace que esta proteína sea considerada uno de los blancos potenciales para la terapéutica con anticuerpos monoclonales.

El receptor del factor de crecimiento epidérmico no es expresado en cantidades detectables en melanocitos normales o células névicas maduras, y es sólo débilmente expresado en nevos displásicos o melanomas en fase de crecimiento radial, pero es fuertemente expresado en melanomas primarios en fase de crecimiento vertical y en melanomas metastásicos.

Los melanocitos segregan una variedad de proteínas de la matriz extracelular, como fibronectina, colágeno tipo IV, laminina, vitronectina, tenascina. Estas proteínas no son encontradas alrededor de melanocitos o células névicas normales, pero pueden ser detectadas alrededor de nidos de melanoma invasivo primario o metastásico.

Las células de melanoma expresan también una variedad de proteínas de la matriz extracelular (integrinas) que participan en la adhesión y migración celular, factores que juegan un rol importante en la motilidad celular, y por lo tanto en la invasión y la metástasis.

Alguno de los mecanismos moleculares que ocurren durante la progresión del tumor melanocítico ha llevado a la identificación de varios marcadores de progresión tumoral del melanoma ${ }^{(96,97,98,99,100)}$.

Muchos casos de nevo y melanoma muestran una expresión uniforme o un gradiente alterado de ARNm o expresión de proteína, algunos melanomas muestran un patrón de expresión muy heterogéneo. Este patrón heterogéneo de expresión antigénica, con focos de alta y baja expresión antigénica de las células tumorales, muestra la correlación con el potencial metastásico del tumor.

El melastatin es un gen melanocítico específico recientemente identificado como un marcador para el pronóstico de metástasis independientemente del espesor del tumor primario en pacientes con melanoma localizado. La expresión de ARNm melastatin se correlaciona inversamente con la progresión de tumores melanocíticos malignos. Niveles elevados de ARNm melastatin se observan en el nevo melanocítico, la pérdida de expresión se observa en los casos de melanoma invasivo con potencial metastásico pero no en los casos de melanomas invasivo primarios cutáneos que no dieron metástasis. Todo melanoma metastásico muestra una pérdida de expresión ${ }^{(101,102,103,}$ 104, 105).

El índice de sobrevida a los cinco años, en melanoma en estadio precoz, disminuye a menos del $50 \%$ en enfermos con metástasis en los ganglios regionales (estadio III según el Comité Americano en Cáncer $[$ AJCC $]$ ). La capacidad de identificar células de melanoma en estos ganglios es importante desde el punto de vista de la estadificación así como también para determinar la terapia adyuvante y los procedimientos adecuados durante el seguimiento de los pacientes. La inmunohistoquímica con anticuerpos mejoró la detección de células de melanoma ocultas en comparación con la coloración con hematoxilina y eosina. Más recientemente, la reacción en cadena de polimerasa reversa (RT-PCR) mostró ser de utilidad para la identificación de células neoplásicas cuando las otras dos técnicas daban resultados negativos. La identificación de marcadores específicos de ARN mensajero, en el ganglio centinela, puede contribuir con el mejor diagnóstico ${ }^{(106)}$.

Un marcador potencialmente útil es la actividad melanoma inhibitoria (MIA; también conocido como una cartílago derivado del ácido retinoico). MIA es una pequeña proteína soluble secretada por las células del melanoma y condrocitos malignos. Fue inicialmente aislada durante la caracterización del factor de inhibición del crecimiento in vitro. Distintos estudios mostraron que este MIA es codificado por un solo gen, localizado en el cromosoma 19, bajo el control de un promotor específico de melanoma. Más recientemente, niveles séricos de la proteína MIA fue encontrado en pacientes con melanoma con enfermedad extendida ${ }^{(107,108,109,110,111,112)}$.

\section{ANGIOGÉNESIS EN EL MELANOMA CUTÁNEO}

En un intento de establecer en qué momento de la progresión tumoral del melanoma maligno se induce 
la proliferación de nuevos vasos sanguíneos, diversos estudios han analizado melanomas incipientes, con un espesor tumoral inferior o igual a $1 \mathrm{~mm}$. Los resultados obtenidos en dichos estudios indican que la capacidad de inducción de angiogénesis es adquirida por los melanomas al pasar de fase radial a fase vertical y, por tanto, que el desarrollo de dicha capacidad puede ser un paso decisivo en la adquisición del fenotipo metastásico en el melanoma maligno cutáneo ${ }^{(113,114,115}$, $116,117,118,119,120,121,122,123,124,125)$.

Según algunos autores la célula característica del melanoma pueden producir, gránulos acumulados en su citoplasma, y secretar varios factores angiogénicos y factores de crecimiento que faciliten la neovascularización, incluyendo histamina, heparina, y factor de necrosis tumoral alfa. Otros investigadores demostraron que además estas células pueden producir y secretar el factor de permeabilidad vascular / factor de crecimiento endotelial vascular, que parece ser uno de los factores angiogénicos más importante. Es sintetizado y secretado por varios tumores y por células normales. Tiene un efecto mitogénico específico sobre las células endoteliales vasculares ya que los receptores para el factor de crecimiento endotelial vascular son expresados selectivamente en estas células. Este factor actúa como una célula mitogénica y regula la neovascularización de varios tumores y otras patologías tisulares.

Se ha observado una directa correlación entre el número de la célula característica del melanoma y la densidad microvascular, lo que sugiere el compromiso de dichas células en la angiogénesis.

Existe una correlación entre la cantidad de células típicas de melanoma y la densidad microvascular en el patrón de unión del tumor. Las células del melanoma en algunas de estas áreas se acumulan mostrando una proliferación dominantemente capilar ${ }^{(126,127,128,129)}$.

\section{MÉTODOS DE DIAGNÓSTICO}

El tema de la biopsia incisión en una lesión, que puede ser un melanoma maligno, fue motivo de innumerables controversias ya que podría causar siembra metastásica. La biopsia por afeitado y el curetaje están contraindicados porque el material obtenido no determina la profundidad de penetración del tumor, dato fundamental para plantear la terapéutica indicada y el pronóstico.

La inmunohistología y las técnicas moleculares son hoy en día decisiones importantes ya que permiten arribar a un pronóstico más certero.
Técnicas moleculares como la hibridación genómica comparativa o la hibridación fluorescente in situ son promesas en el futuro para nuestro medio.

Las técnicas de anticuerpos moleculares han identificado antígenos diferentes por más de 20 años, tanto de las células tumorales como de las células normales. Los antígenos tumorales pueden asociarse a célula diseccionadas, a cortes de tejido y a líquidos del cuerpo, mediante la inmunocitología, inmunohistología y la inmunohistoquímica.

Líneas de antígenos melanocíticos específicos son útiles para el diagnóstico simple, diferencial y de las metástasis, mientras que los antígenos melanocíticos asociados a la progresión resultan interesantes para el pronóstico. Son utilizadas también técnicas inmunológicas como la adhesión de receptores y citoquinas en el suero de pacientes con melanoma ${ }^{(130)}$.

\section{Antígenos asociados al melanoma}

Se clasifican de acuerdo a su naturaleza química, su función o la distribución celular. Son ellos: los gangliosidos primitivos, proteínas oncofetale, receptores de factores de crecimiento, antígenos $H L A$, antígenos pigmentarios asociados, proteínas de la matriz extracelular y moléculas distinguidas. En este contexto, es más sencillo distinguir antígenos de diferenciación y antígenos de progresión, y, desde el diagnóstico diferencial, entre tumores melanocíticos y no melanocíticos. El origen y la capacidad del antígeno de progresión es relevante para el pronóstico. Las pruebas de antigenos de diferenciación, ya sea por inmunocitología o inmunohistología, resultan de gran valor para el diagnóstico por su sensibilidad y especificidad ${ }^{(131,132,}$ 133, 134)

\section{Proteína $S 100$}

La proteína S100 se hace prácticamente en todas las lesiones de tipo melanocíticas, también en el melanoma amelanótico y metástasis encontradas. Es un ácido, proteína calcio-ligando que se aisló originalmente de un extracto de cerebro bovino. Esta proteína no sólo se encuentra fuertemente en el sistema nervioso y en especímenes melanocíticos, también en células de Langerhans, condrocitos y células mioepiteliales. Químicamente es una mezcla de 3 proteínas similares, S100a, S100ab y S100b, de las que existen subunidades alfa-alfa, alfa-beta y beta-beta. Un antisuero de conejo contra la proteína S100 se hace en los diagnósticos de rutina comenzando en los cortes en parafina. El patrón del color es citoplasmático y a veces intranuclear, mayormente la expresión es homogénea, rara vez heterogénea. La sensibilidad es alta, la especificidad baja, ya que los tumores neurales, los condromas, condrosarcomas, algunos carcino- 
mas y tumores mioepiteliales también responden positivamente $^{(136,136)}$.

\section{$H M W-M A A$}

Es un antígeno de alto peso molecular asociado al melanoma (HMW-MAA) es un condrosulfatoproteinglicano, con dos cadenas de alto peso molecular de 420 y $250 \mathrm{kD}$, también conocido como melanoproteinglican. Reacciona con los queratinocitos basales, el epitelio del folículo piloso así como con las células musculares lisas ${ }^{(137)}$.

\section{Antígeno NKI/C3}

Es una glicoproteína 25 - 110 NKI/C3, verificable con un anticuerpo monoclonal, en material parafinado. La sensibilidad en tumores melanocíticos es alta, la especificidad sin embargo es baja, ya que responde positivamente en los tumores neuroendocrinos, en sarcomas y a veces en carcinomas. La expresión del antígeno NKI/C3 en un melanoma no es homogénea ${ }^{(138)}$.

\section{Antígeno $H M B-45$}

La glicoproteína HMB-45 de peso molecular 100 (gp 100) se aplica proporcionalmente en la rutina de los cortes parafinados. La sensibilidad no es alta como para la proteína S100, sin embargo la especificidad es alta. La expresión en los melanomas no siempre es homogénea. De los nevos sólo los juncionales son positivo para HMB- $45^{(139,140)}$.

\section{Indicaciones para la aplicación de anticuerpos contra antígenos de diferenciación melanocítica:}

Existen anticuerpos en parafina contra antígenos de diferenciación melanocítica, para el diagnóstico diferencial histológico de tumores malignos. Los anticuerpos reaccionan contra el filamento intermedio (citoqueratina, vimentina, y desmina) y CD45 (antígeno leucocitario común). Lo más indicado es la aplicación de la proteína anti S100 o HMB-45 para melanomas primarios y micrometástasis en ganglios linfáticos. También en el material de biopsia por aspiración con agujas finas ${ }^{(136)}$.

\section{Antígeno de progresión asociado al melanoma:}

El antígeno de progresión asociado al melanoma (PAMAS) representa receptores para los factores de crecimiento (por ejemplo el receptor para el NGF, receptor para el EGF), factores de crecimiento y moléculas de adhesión.

El receptor transferrina en la citología es un indicador de tumores melanocíticos con displasia y con trans- formación maligna. Ya que se considera que las moléculas de adhesión tienen un rol crucial en la invasión y las metástasis así como con la interacción con los leucocitos. La coexpresión de varias moléculas de progresión en el nevus congénito parece ser un indicador del potencial maligno de estas lesiones ${ }^{(141,142)}$.

\section{Diagnóstico molecular en cambios genéticos en el melanoma:}

La estructura de los cromosomas pueden ser no interpretables a través del análisis, de amplificaciones o de delecciones de $\mathrm{ADN}$ se localizaron cambios aunque recurrentes en los cromosomas 1,6 y $7^{(143)}$.

\section{Diagnóstico inmunológico y molecular en sangre periférica:}

Prueba de tirosinasa en sangre periférica: En las células melanocíticas circulantes, la enzima clave que rige la biosíntesis de la melanina es la tirosinasa. Debido a que los melanocitos no circulan en la sangre y que la tirosinasa en el ARNm libre es muy inestable, la detección del gen tirosina en sangre periférica demuestra la presencia de células melanocíticas circulantes. La reacción de la polimerasa en cadena es una técnica muy sensible para este hallazgo.

Desde la primer descripción del método a través del Smith y colaboradores, equipos diferentes han perfeccionado esta tecnología en un número importante de pacientes con melanoma en fases diferentes de la enfermedad. Se les realizaron exámenes de tirosinasa en la sangre periférica con este método ${ }^{(144,145)}$.

S 100 medidas en la sangre periférica: En 1980 se descubrió la proteína S100. Fue la primera vez que se utilizó para células de melanoma humano. Se ha probado que es un marcador útil para el diagnóstico de melanoma mediante inmunohistoquímica. Ultimamente, se demostró que esta proteína presenta una sensibilidad interesante en el suero de pacientes con melanoma, en fases avanzadas. El método de la prueba está basado en un IRMA (=ensayo inmunorradiométrico). Aproximadamente en el $70 \%$ de los pacientes con señal de metástasis a distancia se reflejó en un aumento de la S100 en el suero, mientras apenas aumentó en pacientes en fases anteriores de la enfermedad. Además, la proteína $\mathrm{S} 100$ se correlaciona con la remisión, durante la terapia, así como con la progresión de la enfermedad.

Después de estos datos preliminares, la proteína $\mathrm{S} 100$ parece ser útil particularmente cuando se supervisan pacientes con melanoma metastásico bajo terapia sistémica ${ }^{(146,147)}$. 


\section{TRATAMIENTO}

La lesión precursora del melanoma y el melanoma maligno de grado 1 son preferentemente removidos por excisión quirúrgica. Estudios recientes apoyan el concepto que las excisiones sean más conservadoras reduciendo el margen de seguridad a un máximo de 3 $\mathrm{cm}$, lo que nos permite cubrir los defectos de la técnica en las zonas flexibles de la piel. El melanoma suele seguir un proceso de progresión ordenado: tras la invasión de las estructuras epiteliales locales, se disemina por vía linfática, alcanzando los ganglios linfáticos regionales, sin omitir estaciones intermedias. Posteriormente sucede la diseminación hematógena. Es por esto que la linfadenectomía regional puede tener un papel importante en el manejo de esta enferme$\operatorname{dad}^{(148,149,150,151,152,153,154)}$. En los últimos años se ha desarrollado la técnica llamada "del ganglio centinela". Consiste en la identificación, mediante técnicas de medicina nuclear, o con la utilización de colorantes vitales, del primer ganglio (ganglio centinela) o del grupo regional afectado en primer lugar por el melanoma, el que, como ya fue comentado, sigue un proceso secuencial en su progresión. Si el ganglio centinela es negativo, la probabilidad que el resto de los ganglios estén afectados parece ser lo suficientemente baja (1\%) como para desestimar una linfadenectomía electiva; por el contrario, si existe afectación metastásica, se debe realizar la linfadenectomía selectiva, pues hasta en un $37 \%$ de estos casos existen más ganglios metastásicos. La linfogammagrafía prequirúrgica permite visualizar los canales linfáticos eferentes del MM (estudio dinámico) y posteriormente el o los ganglios centinelas. Asimismo, nos permite objetivar los territorios linfáticos "en riesgo" de presentar micrometástasis, puesto que nos proporciona un mapa linfático y permite observar si existe más de una área de drenaje, lo cual no es infrecuente en los melanomas localizados en tronco, abdomen y región cervical, evidenciándose hasta en un $49 \%$. Por otra parte, la linfogammagrafía demuestra con frecuencia discordancias con los patrones de drenaje pronosticados clínicamente y puede alterar el tratamiento quirúrgico hasta en un tercio de los pacientes.

La linfogammagrafía nos ayuda en la localización del ganglio centinela, permitiendo realizar un marcaje externo cutáneo de la región donde se encuentra el ganglio centinela para, posteriormente, realizar la incisión quirúrgica y la localización intraoperatoria del ganglio centinela dirigida con la sonda de detección. La localización del ganglio centinela puede realizarse el mismo día o al día siguiente de la linfogammagrafía, lo que permite una gran flexibilidad en la programación y manejo de los pacientes ${ }^{(155,156,157,158,159,160,161,162,163,164,168,166,167,168 \text {, }}$ 169, 170, 171, 172, 173, 174, 175)

Un desafío especial es poder reconocer oportunamente las lesiones pigmentarias sospechosas con sus corres- pondientes grupos de riesgo y la posibilidad de prevenir las lesiones precursoras y la eliminación prematura del melanoma primario, preferentemente en la fase de crecimiento inicial ${ }^{(176)}$.

La radioterapia no es útil en el tratamiento del tumor primario, y está discutida su utilidad como tratamiento adyuvante. Se ha sugerido que la radioterapia post operatoria mejora el control local, y quizás la supervivencia, de pacientes con melanomas del área de cabeza y cuello.

Con la quimioterapia combinada se consiguen índices de respuesta objetiva mayores que con la monoterapia, entre el $25 \%$ y el $45 \%$, pero no se ha demostrado que incrementen la supervivencia. La probabilidad de respuesta a la quimioterapia de las lesiones cutáneas y ganglionares es de un $20 \%$, mientras que para las metástasis viscerales es de menos del $5 \%$.

La quimioterapia regional puede ser útil para la recidiva del melanoma en forma de satelitosis o metástasis en tránsito cuando sucede en una extremidad, o bien para el tratamiento de las metástasis hepáticas.

La combinación de quimioterapia con citoquinas y/o interferones (quimioinmunoterapia) ha ofrecido resultados esperanzadores en estudios fase I y II, pero los datos procedentes de ensayos fase III no han demostrado un aumento de la supervivencia de los pacientes.

El melanoma es uno de los tumores en los que más se ha investigado la utilidad de los agentes moduladores de la respuesta biológica, como los interferones y las interleuquinas. Los agentes más utilizados en el melanoma metastásico han sido el IFN alfa y la IL-2. Ambos agentes consiguen respuestas objetivas en el $15 \%$ a $20 \%$ en pacientes con melanoma metastásico, pero por lo general, sólo responden en pacientes con buen estado funcional y mínima carga de enfermedad metastásica, limitada a piel, a ganglios y a pulmones.

Los interferones han demostrado un beneficio terapéutico como tratamiento adyuvante en melanoma maligno cutáneo resecado con alto riesgo de recidiva ${ }^{(177,178,179)}$.

Otra posibilidad terapéutica es la utilización de vacunas tumorales. Actualmente se trabaja con antígenos tumorales purificados específicos de melanoma, capaces de provocar una respuesta inmune en el huésped. La vacunación de enfermos con melanoma de estado IV con sus propias células dendríticas preincubadas con antígeno tumoral presente en el melanoma, supuso una reactivación selectiva de sus defensas frente al melanoma. En concreto se incubaron células dendríticas maduras generadas in vitro, a partir de monocitos, con el péptido de melanoma Mage-3Al. La administración de las células dendríticas de manera subcutánea e 
intradérmica permitió la expansión de linfocitos T CD8+ anti - tumorales específicos de melanoma. Como resultado se obtuvieron regresiones de metástasis en 6/11 pacientes ${ }^{(180)}$.

Sin embargo, la elaboración de las vacunas es difícil técnicamente, al precisarse gran cantidad de tejido tumoral. Además, el paciente debe tener un haplotipo $\mathrm{HLA}$ capaz de reconocer al antígeno específico de melanoma que incluye la vacuna ${ }^{(1,181,182,183)}$.

\section{PAUTAS PARA EL SEGUIMIENTO DEL MELANOMA CUTÁNEO ESTADIO I - II}

La periodicidad del seguimiento se debe establecer en relación con el espesor del melanoma resecado:

$\checkmark$ Lesiones menores a 0,76 mm: control semestral para los primeros dos años y anual hasta el quinto año.

$\checkmark$ Lesiones entre $0,76 \mathrm{~mm}$ y $1,5 \mathrm{~mm}$ : seguimiento trimestral durante dos años y semestral hasta el quinto año.

$\checkmark$ Lesiones mayores a 1,5 mm: control trimestral durante tres años y semestral hasta los cinco años.

El seguimiento de los pacientes que han presentado un melanoma maligno debe continuarse durante toda la vida, debido a la posibilidad de presentar una recurrencia tardía de la enfermedad o un segundo melanoma. El melanoma puede permanecer clínicamente inaparente y los pacientes pueden presentar enfermedad recurrente o metastásica, incluso décadas después del diagnóstico inicial. El compromiso pulmonar cuando existe invasión canalicular puede manifestarse con tos seca, con o sin hemóptisis o como disnea secundaria a invasión parenquimatosa. La invasión del SNC se expresa en forma variable según su topografía: cefaleas, crisis epilépticas, trastornos de conducta o parálisis de pares craneanos. Si la afectación es medular se aprecian trastornos motores, sensitivos o vegetativos agudos. Las manifestaciones clínicas de las metástasis óseas son tardías e inespecíficas; dolor óseo y fracturas patológicas. La aparición de anemia microcítica sin causa aparente puede deberse a pérdidas microscópicas en la luz intestinal como consecuencia de metástasis en la mucosa gástrica. La invaginación de un asa intestinal con metástasis de melanoma puede determinar dolor abdominal agudo con o sin masa palpable.

A los pacientes se les recomienda: - evitar exposiciones solares intensas y utilizar protección mediante ropa, sombreros y pantallas solares con factor de protección mayor de 15; - autoexamen periódico de la piel; - alertar sobre eventuales riesgos de embarazos o tratamientos hormonales; - control de lesiones pigmentadas en familiares de primer grado; - insistir sobre el concepto de control durante toda la vida.
Los exámenes complementarios que deben solicitarse para el seguimiento de un paciente sin evidencia clínica de metástasis viscerales de melanoma maligno son la radiografía de tórax y el hepatograma con $\mathrm{LDH}$. El patrón anormal que sugiere la presencia de metástasis hepáticas es la elevación de los niveles de $\mathrm{LDH}$. ${ }^{(184,185,186,}$ 187, 188, 189, 190).

\section{SUIMIMARY}

Advance malignant melanoma is generated from proliferating dendritic (nevic) cell progenitors. They are important on the histogenesis and risk of tumor development. From $30 \%$ to $37 \%$ from high air-digestic track melanoms, there are associated with premalignant cell dendritic lesions. Histophatological approaches agree in consider size of tumor, atypical cells, distribution of this cells and borders of lesion as valued markers. Major advances in tumor immunology, have led to understand tumor cell-T cell interactions. A number of melanom associated antigens have been identified and molecularly characterized.

\section{KEY WORDS}

Melanoma - Nevus - Precocious Diagnosis - Inmunology - Angiogenesis - Metastasis.

\section{CORRESPONDENCIA}

Bartolomé Mitre $\mathrm{N}^{\circ} 1371$ e/ Talcahuano y Uruguay $4^{\circ}$ M. (1036) Capital Federal. Bs. As. Argentina

Tel/Fax: 0054-11-4372- 0444

e mail:drabaudo@yahoo.com.ar

\section{BIBLIOGRAFÍA}

1. Rosell R, Abad A, Monzó M, Bardanas A. Manual de oncología clínica y molecular. Arán Ediciones. 2000; 405-16.

2. Castellano Reyes JJ, Vicente Barreto MM, Domínguez Sarmiento S. Melanoma maligno de la cavidad oral: A propósito de un caso. Av Odontoestomatol. 1995; 11:283-6.

3. Ohashi K, Kasuga T, Tanaka N, Enomoto S, Horiuchi J, Okada N. Malignat melanomas of the oral cavity: Heterogeneity of pathological and clinical features. Vilchows Aechiv A Pathol Anat. 1992; 420: 43-50.

4. Kaugars G, Heise A, Riley W, Abbey L, Svirsky J. Oral melanotic macules. A review of 353 cases. Oral Surg Oral Med Oral Pathol. 1993; 76: 59-61. 
5. Gerard E, Fidanza J, Truchetet F. Melanoma malin de la muqueause buccale. Actualités Odonto-Stomatologiques. 1991; 174: 237-46.

6. Gaze M, Kerr G, Smyth J. Mucosal melanomas of the head and neck. The Scottish experience. Clinical Oncology. 1990; 2: 277-83.

7. Kato T, Takematsu H, Tomita Y, Takahashi M, Abe R. Malignant melanoma of mucous membranes. A clinicopathologic study of 13 cases in japaneses patients. Arch Dermatol. 1987; 123: 216-20.

8. Neville BW, Damm DD, Allen CM, Bouquot JE. Oral and maxillofacial pathology. Philadelphia: WB Saunders. 1995; p. 259-322.

9. Peckitt NS, Wood GA. Malignant melanoma of the oral cavity. A case report. Oral Surg Oral Med Oral Pathol. 1990; 70: 161-4.

10. Takagi M, Ishikawa G, Mori W. Primary malignant melanoma of the cavity in Japan. Cancer. 1974; 34: 358-70.

11. Tanaka N, Amagasa T, Iwaki H, et al. Oral malignant melanoma in Japan. Oral Surg Oral Med Oral Pathol. 1994; 78 : 81-90.

12. Nacht S, Subhash JS. Melanina: biopolímero esencial para la supervivencia. Act. Terap. Dermatol. 1997; 20: 119-29.

13. Ortel B, Gange RW. UVA Action Spectra for Erythema and Pigmentation, en: F. Urbach: Biological Reponses to Ultraviolet A Radiation. Valdenmar Publishing Co., Overland Park, KA. 1992; 79-82.

14. Pugliese PT, Christensen MS, Nacht S, Walmer S. Uva and UVB Protection Against Lipid Peroxidation by a Melanincontaining Sunscreen, en: Zeise L, Chedekel MR and Fitzpatrick TB: Melanin: Its Role in Human Photoprotection. Valdenmar Publishing Co., Overland Parck, KA. 1995; 271-6.

15. Prota G. Melanins and melanogenesis. Academic Press, Inc., San Diego. 1992, pp. 4-13.

16. Prota G. The chemistry of melanins and melanogenesis, en : Herz W, Kirby GW, Moore RE, Steglich W, Tamm Ch. Progress in the chemistry of organic natural products. Spriger - Verlag, New York. 1995; pp. 94-146.

17. Eisen Z, Wolff K, Freedberg M, Austen KF. Dermatology in general medicine. MacGraw - Hill, New York. 1987; pp. 251-8.

18. Lang G. Proc. 17th IFSCC International Congress. 1992; 3: 1072-94.

19. White E, Kirkpatrick CS, Lee JA. Case-control study of malignant melanoma in Washington State. I. Constitutional factors and sun exposure. Am J Epidemiol. 1994; 139: 857-68.

20. Whiteman D, Green A. Melanoma and sunburn. Cancer Causes Control. 1994; 5: 564-72.

21. Ródenas JM, Delgado - Rodríguez M, Herranz MT,
Tercedor J, Serrano S. Sun exposure, pigmentary traits, and risk of cutaneous malignant melanoma: a case control study in a Mediterranean population. Cancer Causes Control. 1996; 7: 275-83.

22. Fitzpatrick TB. The validity and practicality of sun - reactive skin types I through VI. Arch Dermatol Surg Oncol. 1988; 14: 393-408.

23. Augustsson A. Melanocity naevi, melanoma and sun exposure. Acta Dermatol Venereol (Stockh). 1991; 166 (Supl): 1-34.

24. Beitner H, Norell SE, Ringborg U, Wennersten G, Mattson B. Malignant melanoma: aetiological importance of individual pigmentation and sun exposure. $\mathrm{Br} \mathrm{J}$ Dermatol. 1990; 122: 43-51.

25. Evans RD, Kopf AW, Lew RA, Rigel DS, Bart RS, Friedman $\mathrm{RJ}$ et al. Risk factors for the development of malignant melanoma I: review of case-control studies. J Dermatol Surg Oncol. 1988; 14: 393-408.

26. Holman CD, Armstrong BK. Pigmentary traits, ethnic, origin, beningn nevi, and family history as risk factors for cutaneous malignant melanoma. J Natl Cancer Inst. 1984; 72: 257-66.

27. Lancaster HO. Some geographical aspects of mortality from melanoma in Europeans. Med. J. Aust. 1956; 1: 1082 -7.

28. Green A, MacLennan R, Siskind V. Common acquired naevi and the risk of malignant melanoma. Int J Cancer. 1985; 35: 297-300.

29. Holly EA, Aston DA, Cress RD, Ahn DK, Kristiansen JJ. Cutaneous melanoma in women. II. Phenotypie characteristies and other host - related factors. Am J Epidemiol. 1995; 141: 934-42.

30. Ródenas López JM. Factores de riesgo del melanoma cutáneo (II). Factores de riesgo individuales: nevos melanocíticos. Piel. 1998; 13: 191-8.

31. Swerdlow AJ, English J, MacKie RM, O'Doherty CJ, Hunter JAA, Clark J et al. Bening melanocytic naevi as a risk factor for malignant melanoma. Br Med J. 1986; 292: 1555- 9.

32. Skender - Kalnenas TM, English DR, Heenan PJ. Bening melanocytic lesions: risk markers or precursors of cutaneous melanoma. J Am Acad Dermatol. 1995; 33: 1000-7.

33. Grobb JJ, Gonvernet J, Aymar D, Mostaque A, Romano MH, Collet AM, et al. Count of benign melanocytic nevi as a major indicator of risk for nonfamilial nodular and superficial spreading melanoma. Cancer. 1990; 66: 387- 95.

34. Grulich JJ, Bataille V, Swerdlow AJ, Newton - Bishop JA, Cuzick J, Hersey P, et al. Naevi and pigmentary characteristics as risk factors for melanoma in a high - risk population: a case control study in New South Wales, Australia. Int J Cancer. 1996; 67: 485-91.

35. Mackie RM, English J, Aitchison TC, Fitzsimons CP, Wilson $P$. The number and distribution of benign pigmented moles (melanocytic naevi) in a healthy British population. Br J Dermatol. 1985; 113: 167-74. 
36. de Pablo A. Simposio: Melanoma maligno. Act. Terap. Dermatol. 1997; 20: 54-7.

37. Rampen F. Malignant melanoma: sex differences in survival after evidence of distant metastasis. Br J Cancer. 1980; 42: 52-7.

38. Shaw HM, McGovern VJ, Milton GW, Farago GA, McCarthy WH. Malignant melanoma: influence of site of lesion and age of patient in the female superiority in survival. Cancer. 1980; 46: 2731-5.

39. Holly EA, Weiss NS, Liff JM. Cutaneous melanoma in relation to exogenous hormones and reproductive factors. J Natl Cancer Inst. 1983; 70: 827-31.

40. Gallagher RP, Elwood JM, Hill GB, Coldman AJ, Threlfall WJ, Spinelli JJ. Reproductive factors, oral contraceptives and risk of malignant melanoma: Western Canada Melanoma Study. Br J Cancer. 1985; 52: 901-7.

41. Holly EA, Cress RD, Ahn DK. Cutaneous melanoma in women. III. Reproductive factors and oral contraceptive use. Am J Epidemiol. 1995; 141: 943-50.

42. Holman CD, Armstrong BK, Heenan PJ. Cutaneous malignant melanoma in women: exogenous sex hormones and reproductive factors. Br J Cancer. 1984; 50: 673-80.

43. Zanetti R, Franceschi S, Rosso S, Bidoli E, Colonna S. Cutaneous malignant melanoma in females: the role of hormonal and reproductive factors. Int J Epidemiol. 1990; 19: 522-6.

44. Clark WH, Tucker MA. Problems with lesions related to the development of malignant melanoma: common nevi, dysplastic nevi, malignant melanoma in situ, and radial growth phase malignant melanoma. Human Pathology. Vol 29, $\mathrm{N}^{\circ}$ 1. 1998.

45. Guerry D, Synnestvedt M, Elder DE, et al. Lesions from tumor progression - The invasive radial growth phase of melanoma is common, incapable of metastasis, and indolent. J Invest Dermatol. 1993; 100: 342-5 (Suppl).

46. Clark WH, Jr. The nature of cancer: Morphogenesis and progressive (self) disorganization in neoplastic development and progression. Acta Oncologica. 1995; 34: 3-21.

47. Ackerman AB. Melanoma in situ and matters that transcend it. Institute for Dermatopathology Thomas Jefferson University. Philaderphia.

48. Elder DE, Clark WH, Jr. Tumor progression and prognosis in malignant melanoma, in Elder DE (ed): Pathobiology of malignant melanoma, pigment cell series, Vol. VIII, Basel, Karger. 1987; pp. 51-80.

49. National Institutes Of Health Consensus Panel:Workshop without walls. 1991 Bethesda, MD, 1991.

50. Ackerman AB, Cerroni L, Kerl H. Pitfalls in histopathologic diagnosis of malignant melanoma. Philadelphia, Lea \& Febiger. 1994.

51. Clark WH, Jr, Goldstein AM, Tucker MA. Prospectives for cutaneous malignant melanoma: Considerations of the precursor state and hereditability. Br Med Bulletin 51; 1995.

52. Clark WH, Jr, Tucker MA, Goldstein AM. Parenchymalstromal interactions in neoplasia. Theoretical considerations and observations in melanocytic neoplasia. Acta Oncol. 1995; 34: 749-57.

53. Mihm MC, Murphy GF. Malignant melanoma in situ: an oxymoron whose time has come.

54. Reed RJ. Melanoma in situ: images, segments, apellations, and implications. Human Pathology. Vol 29, $\mathrm{N}^{\circ} 1$. 1998.

55. Cotran R, Kumar V, Robbins S: Pathologic basis of disease, (ed 5) Philadelphia, WB Saunders. 1994; pp. 274.

56. Elder DE, Murphy GF. Atlas of tumor pathology: Melanocytic tumors of the skin, (Series 3, Vol. 2) Bethesda, MD, Armed Forces Institute Of Pathology. 1991; pp. 110.

57. Clark WH, Jr, Elder DE, Van Horn M. The biologic forms malignant melanoma. Hum Pathol. 1986; 17: 443-50.

58. McGovern VJ, Mihm MC, Jr, Bailly C, et al. The classification of malignant melanoma and its histologic reporting. Cancer. 1973; 18: 12-21.

59. Sagebiel RW. Diagnosis and management of premalignant melanocytic proliferations. Pathology. 1985; 17:285-90.

60. García Muret MP. Diagnóstico diferencial de los tumores pigmentados. Servicio de Dermatología. Hospital General de Catalunya. Barcelona.

61. Miller M, Ackerman AB. How accurate are dermatologists in the diagnosis of melanoma? Degree of accuracy and implications. Arch Dermatol. 1992; 128: 559-60.

62. Grob J. Tumeurs noires cutanées. Orientation diagnostique. Rev. Prat. 1991; 41:2097-102.

63. Sober AJ, Rodees AR, Mihm MC, Fitzpatrick TB. Neoplasms: Malignant Melanoma. En:Wolff K, Freedberg IM, Austen KF, eds. Dermatology in General Medicine, vol. 1. Nueva York: McGraw - Hill. 1987; pp. 947-66.

64. Mackie R. Tumores cutáneos: melanoma maligno. En: Rook A, Wiliinson DS, Ebling FJG, Champion RH, Burton JL, eds. Tratado de Dermatología. Barcelona. Doyma. 1988; pp. 2652-67.

65. Armijo M, Camacho F, Aliaga A. Tumores pigmentarios. Nevus pigmentocelulares. Coristomas melanocíticos. Melanomas. En: Armijo M, Camacho F eds. Tratado de Dermatología. Madrid: Aula Médica. 1998; pp. 485-508.

66. Mcckie RM. Melanocytic naevi and malignant melanoma. En: Champion RH, Burton JL, Burns DA, Breathnach SM eds. Textbook of Dermatology, 6th ed. Oxford: Blackwell Science Ltd. 1998; pp. 1717-52.

67. Rhodes AR. Benign neoplasias and hyperplasias of melanocytes. En: Fitzpatrick TB, Eisen AZ, Wolff K, Freedberg IM, Austen KF eds. Dermatology in General Medicine, 5th ed. New York: McGraw Hill, Inc. 1999; pp. 1018-59. 
68. Chiu NT, Weinstock MA. Melanoma of oronasal mucosa. Population - based analysis of ocurrence and mortality. Arch Otolaryngol Head Neck Surg. 1996; 122: 985-8.

69. Rapini RP, Golitz LE, Greer RO, Krekorian EA, Pulson T. Primary malignant melanoma of the oral cavity: a review of 177 cases. Cancer. 1985; 55: 1543-51.

70. Bucci E, Mignogna MD, Lo Muzio L Primary malignant melanoma of the oral cavity: a case report. J Oral Maxillofac Surg. 1989; 47: 621-2.

71. Medina JE, Canfield V. Malignant melanoma of the head and neck. En: Myers EN, Suen JY. Cancer of the head and neck. Philadelphia:WB Saunders Co. 1996; pp. 160-83.

72. Díaz Rubio E, García Conde J. Oncología Clínica Básica. Arán Ediciones. 2000; 499-510.

73. Duray PH. Dysplatic Nevus. En: Demis J, Dobson RL, McGuik JS, eds. Clinical Dermatology. Filadelfia: JB Lippincott. 1989; pp. 1-11.

74. Pérez IR, Fenske NA, Brozena SJ. Malignant melanoma: differential diagnosis of the pigmented lesion. Semin Surg Oncol. 1993; 9: 168-73.

75. Bolognia JL. Reticulated black solar lentigo (*ink spot* lentigo). Arch Dermatol. 1992; 128: 934-40.

76. Shelley WB, Shelley ED. Nevi and melanomas. En: Advanced Dermatologic Diagnosis. Filadelfia WB Saunders Co. 1992; 958-65.

77. Massimo J, Samara R, Hauviller V, Pueyo S. Nevus de Ota. Rev Argent. Dermatol. 1997; 78: 58-61.

78. Lever W, Schaumburg - Lever G. Nevus of Ota and Ito. Dermal melanocytic hamartoma. In Histopathology of the skin, (7ed). 1991; p. 725.

79. Hidano A, Mishima Y, Nomoto K. Pigmentation deo mugueuses dans la naevus d'Ota. Bull. Soc. Franc. Dermatol. Syph. 1957; 3: 287.

80. Kudo S, Arao R. Nevus of Ota. In: Nishiyama S, Shimao S, Hori Y, (eds): Current treatment of skin diseases. Tokyo. Nankodo. 1987; p. 214.

81. Cowan TH, Balistrocky M. The nevus of Ota or oculodermal melanocytosis. Arch. Ophthalmol. 1961; 65: 483.

82. Hwang SW, Chung TB, Solin HS, et al. The frecuency and clinical observation of Ota's nevus. Korean J Dermatol. $1984 ; 22: 22$.

83. Amici J, Vidal J, Bernard P, et al. Nevus of Ota and benign cutaneous blue nevus associated with malignant cerebromeningeal melanoma. Ann. Dermatol.Venereol. 1991; 118: 707-9.

84. Shaffer D, Walker K, Weiss G. Malignant melanoma in a Hispanic male with nevus of Ota. Dermatology. 1992; 185: 146-50.

85. Dorsay CS, Montgomery H. Blue nevus its distinction from Mongolian spot and the nevus of Ota. J Invest. Dermatol. 1954; 22: 225.
86. The new England of Medicine. Vol 332, N 10. 1995.

87. Goldenhersh MA, Savin RC, Barnhill RL, Stenn KS Malignant blue nevus: case report and literature review. J Am Acad Dermatol. 1988; 19: 712-22.

88. Tucker MA, Greene MH, Clark WH, Jr, Kraemer $\mathrm{KH}$, Fraser MC, Elder DE. Dysplastic nevi on the scalp of prepubertal children from melanoma - prone families. J Pediatr. 1983; 103: 65-9.

89. Greene MH, Clark WH, Jr, Tucker MA, Kraemer KH, Elder DE, Fraser MC. High risk of malignant melanoma in melanoma - prone families with dysplastic nevi. Ann Intern Med. 1985; 102: 458-65.

90. Clark WH, Jr, Reimer RR, Greene M, Ainsworth AM, Mastrangelo MJ. Origin of familial malignant melanomas from heritable melanocytic lesions: "the B - K mole syndrome". Arch Dermatol. 1978; 114: 732-8.

91. Walsh N, Crotty K, Palmer A, McCarthy S. Spitz versus spitzoid malignant melanoma: an evaluation of the current distinguishing histopathologic criteria. Human Pathology. Vol 29, $\mathrm{N}^{\circ}$ 10. 1998.

92. Steiner A, Pehamberger H, Binder M, Wolf K. Pigmented Spitz nevi: improvement of the diagnostic accuracy by epiluminescence microscopy. J Am Acad Dermatol. 1992; 27: 697-701.

93. Casso EM, Grin - Jorgensen CM, Grant - Kels JM. Spitz nevi. J Am Acad Dermatol. 1992; 27: 901-13.

94. Smith KJ, Barrett TL, Skelton HG III, Lupton GP, Graham JH. Spindle cell and epithelioid cell nevi with atypia and metastasis (malignant Spitz nevus). Am J Surg Pathol. 1989; 13: 931-9.

95. Clark Wh Jr, Elder DE, Guerry D IV, et al. A study of tumor progression:The precursor lesions of superficial spreading and nodular melanoma. Hum Pathol. 1984; 15: 1147-65.

96. Mordoh A. Inmunología del melanoma. Dermatología Argentina. Vol 4, N 1. 1998.

97. Houghton AN, Real FX, Davis LI, Cordón - Cardo C, Old LI. Phenotypic heterogeneity of melanoma: Relation to the differenciation program of melanoma cells. J Exp Med. 1987; 165: 812.

98. Dippold WG, Lloyd KO, Li LTC, Ikeda H, Oettgen HF. Cell surface antigens of human malignant melanoma: Definition of six antigenic systems with mouse monoclonal antibodies. Proc Natl Acad Sci USA. 1980; 77: 6114.

99. Tronnier M, Alexander M, Wolff H. Adhesion molecule expression in normal skin and melanocytic lesions. J Cutan Pathol. 1997; 24: 278-85.

100. Weil - Hillman G, Fisch P, Prieve AF, Sosman JA, Hank JA, Sondal PM. Lymphokine activated killer activity induced by in vivo interleukin 2 therapy: Predominant role for lymphocyte with increased expression of CD2 and Leu 19 antigens but negative expression of CD16 antigens. Cancer Res. 1989; 49: 3680. 
101. Deeds J, Cronin F, Ducan LM. Patterns of melastatin mRNA expression in melanocytic tumors. Human Pathology. Vol 31, $\mathrm{N}^{\circ} 11.2000$.

102. Elder D. Tumor progresión, early diagnosis and prognosis of melanoma. Acta Oncol. 1999; 38: 535-47.

103. Duncan LM. Prognostic indicators in melanoma. Adv Dermatol. 1999; 15: 489-517.

104. Duncan LM, Deeds J, Cronin FE, et al. Melastatin expression and prognosis in cutaneous malignant melanoma. J Clin Oncol. 2000 (in press).

105. Letts G, Cronin F, Atwell M, et al. Melastatin mRNA expression in spitz nevi. J Cutan Pathol. 1999; 26: 459.

106. Bostick P, Morton D, Kelly R, et al.Valor pronostico de las metástasis ocultas en ganglio centinela en melanoma temprano. Journal of clinical Oncology. 1999;17(10): 3238-44.

107. Pérez RP, Zhang P, Bosserhoff AK, Buettner R, Abu-Hadid M. Expression of melanoma inhibitory activity in melanoma and nonmelanoma. Tissue specimens. Human Pathology. Vol 31, $\mathrm{N}^{\circ} 11.2000$.

108. Bosserhoff AK, Kondo S, Moser M, et al. Mouse CD RAP/MIA gene: Structure, localization, and expression in cartilage and chondrosarcoma. Developmental Dynamics. 1997; 208: 516-25.

109. van Gronigen JJ, Bloemers HP, Swart GW. Identification of melanoma inhibitory activity and other differentially expressed mRNAs in human melanoma cell lines with different metastatic capacity by messenger RNA differential display. Cancer Res. 1995; 55: 6237-43.

110. Bosserhoff AK, Kaufmann M, Kaluza B, et al. Melanoma inhibiting activity, a novel serum marker for progression of malignant melanoma. Cancer Res. 1997; 57: 3139-53.

111. Bosserhoff AK, Hein R, Bogdahn U, et al. Structure and promoter analysis of the gene encoding the human melanoma - inhibitoring protein MIA. J Biol Chem. 1996; 271: 490-5.

112. Koehler MR, Bosserhoff AK, von Beust G, et al. Assignment of the human melanoma inhibitory activity gene (MIA) to 19q13.32 q13.33 by fluorescence in situ hybridisation. Genomics. 1996; 35: 265-7.

113. Marcoval Caus J, Moreno Carazo A, Fabra Fres A. Angiogénesis en el melanoma cutáneo. Piel. 1998; 13: 109-11.

114. Folkman J, Kklagsbrun M. Angiogenic factors. Science. 1987; 235: 442-7.

115. Barnhill RL, Wolf JE. Angiogenesis and the skin. J Am Acad Dermatol. 1987; 16: 1226-42.

116. Arbister JL. Angiogenesis and the skin: a primer. J Am Acad Dermatol. 1996: 34: 486-97.

117. Ríos L, Fernández J. Angiogénesis peritumoral y metástasis. Piel. 1995; 10: 178-86.
118. Denijn M, Ruiter DJ. The possible role of angiogenesis in the metastatic potential of human melanoma. Clinicopathological aspects. Melanoma Res. 1993; 3: 5-14.

119. Weidner N, Semple JP, Welch WR, Folkman J. Tumor angiogenesis and metastasis. Correlation in invasive breast carcinoma. N Engl J Med. 1991; 324: 1-8.

120. Folkman J. Wath is the evidence that tumors are angiogenesis dependent? J Natl Cancer Inst. 1990; 82: 4-6.

121. Srivastava A, Laidler P, Hughes LE, Woodcoock J, Shedden EJ. Neovascularization in human cutaneous melanoma: a quantitative morphological and Doppler ultrasound study. Eur J Cancer Clin Oncol. 1986; 22: 1205-9.

122. Fallowfield ME, CooK MG. Lymphatics in primary cutaneous melanoma. Am J Surg Pathol. 1990; 14: 370-4.

123. Srivastava A, Hughes LE, Woodcoock J, Shedden EJ. The significance of blood flow in cutaneous malignant melanoma demonstrated by Doppler flowmetry. Eur J Surg Oncol. 1986; 12: 13-8.

124. Marcoval J, Moreno A, Graells J, Vidal A, Escribà JM, Peyrí J, et al. Vascular density and survival in cutaneous melanoma. Br J Dermatol. 1996; 134: 809-10.

125. Marcoval J, Moreno A, Graells J, Vidal A, Escribà JM, García - Ramírez M, et al. Angiogenesis and malignant melanoma. Angiogenesis is related to the development of vertical ( tumorigenic) growth phase. J Cutan Pathol. $1997 ; 24: 212-8$.

126. Tóth T, Tóth - Jakatics R, Jimi S, Takebayashi S, Kawamoto N. Cutaneous malignant melanoma: correlation between neovascularization and peritumor accumulation of mast cells overexpressing vascular endothelial growth factor. Human Pathology. Vol 31, $\mathrm{N}^{\circ}$ 8. 2000.

127. Boesiger J, Tsai M, Maurer M, et al. Mast cells can screte vascular permeability factor/vascular endothelial cell growth factor and exhibit enhanced release after inmunoglobulin $\mathrm{E}$ - dependent upregulationt of FC, receptor I expression. J Exp Med. 1998; 188: 1135-45.

128. Ferrara N, Davis - Smyth T. The biology of vascular endothelial growth factor. Endocr Rev. 1997; 18: 4-25.

129. Viglietto G, Romano A, Maglione D, et al. Neovascularization in human germ cell tumors correlates with a marked increase in the expression of the vascular endothelial growth factor but not the placenta - derived growth factor. Oncogene. 1996; 13: 577-87.

130. Bröcker EB, Bastian BC, Dummer W. Von der inmunologischen zur molekularen melanomdiagnostik. Zeitschrift für Hautkrankheiten, H+G 3 (72) 168-72. 1997.

131. Bröcker EB, Suter L, Brüggen J, Ruiter DJ, Macher E, Sorg C. Phenotypic dynamics of tumor progression in human malignant melanoma. Int J Cancer. 1985; 36: 29-35.

132. Holzmann B, Bröcker EB, Lehmann JM, Ruiter DJ, Sorg C, Riethmüller G, Johnson JP. Tumor progression in human malignant melanoma: Fives stages defined by their antigenic phenotypes. Int J Cancer. 1987; 39: 466-71. 
133. Muijen GNP van, Ruiter DJ, Hoefakker S, Johnson JP. Monoclonal antibody PALMl recognizes the transferring receptor and is a progression marker in melanocytic lesions. J Invest Dermatol. 1990; 95: 65-9.

134. Ostmeier $\mathrm{H}$, Suter $\mathrm{L}$. The $\mathrm{Ki}-67$ antigen in primary human melanomas - its relatioship to mitotic rate and tumor thickness and its stability. Arch Dermatol Res. 1989; 281: 173-7.

135. Cochran AJ, Wen DR, Herschman HR, Gaynor RB. Detection of S-100 protein as an aid to the identification of melanocytic tumors. Int J Cancer. 1982; 30: 295-7.

136. Cochran AJ, Wen DR, Morton DL. Occult tumor cells in the lymphnodes of patients with pathological stage I malignant melanoma. Am inmunohitological study. Am J Surg Pathol. 1988; 12: 612-8.

137. Giacomini P, Natali PG, Ferrone S. Analysis of in the interactions between human high - molecular weight melanoma - associated antigens and the monoclonal antibodies to three antigenic determinants. J Inmunol. 1985; 135: 696-702.

138. Vennegar C, Calafat J, Hageman PH, van Bultenen F, Janssen H, Kolk A, Rümke PH. Biochemical characterization and cellular localization of a fermalin - resistant melanoma - associated antigen reacting with monoclonal antibody NKI/C3. Int J Cancer. 1985; 35: 287-95.

139. Bakker ABH, Schreurs MWJ, de Boer AJ, Kawakami Y, Rosenberg SA, Adema GJ, Figdor CG. Melanocyte lineage - specific antigen gp 100 is recognized by melanoma-derived tumorinfiltrating lymphocytes. J Exp Med. 1994; 179: 1005-9.

140. Grown AM, Vogel AM, Hoak D, Gough F, McNutt MA. Monoclonal antibodies specific for melanocytic tumors distinguish subpopulations of melanocytes. Am J Pathol. 1986; 123: 195-203.

141. Klein CE, Steinmayer TH, Kaufmann D, Weber L, Brücker EB. Identification of a melanoma progression antigen as integrin VLA-2. J Invest Dermatol. 1991; 96: 281-4.

142. de Wit PEJ, Moretti S, Weterman MAJ, Defize BLMK, Muijen GNP van, Gianotti B, Ruiter DJ. Epidermal growyh factor receptor is a progression marker in human melanocytic lesions. J Invest Dermatol. 1992; 99: 168-73.

143. Thompson FH, Emerson J, Olson S, Weinstein R, Leavitt SA, Leong SPL, Emerson S, Trent JM, Nelson MA, Salmon $\mathrm{SE}$, Teatle R. Cytogenetics of 158 patients with regional or disseminated melanoma - subset analysis of near diploid and simple karyotypes. Cancer Genet Cytogenet. 1995; 83: 93-104.

144. Brossart P, Keiholz U, Willhauck W. Hematogenous spread of malignant melanoma cells in different stages of disease. J Invest Dermatol. 1993; 101: 887-9.

145. Fross AJ, Guille MJ, Occlestone NL, Hykin PG, Hungerford JL, Lighthan S. The detection of melanoma cells in peripheral blood by reverse - transcription plymerase chain reaction. Br J Cancer. 1995; 72: 155-9.
146. Gaynor R, Irie R, Morton D, Herschman HR. S100 protein is present in cultured human malignant melanomas. Nature. 1980; 286: 400-1.

147. Hansson LO. S100 protein: A new valuable prognostic serum marker in malignant melanoma. Melanoma Res. 1996 , in press.

148. Kaufmann R. Operative therapie kutaner melanome. Zeitschrift für Hautkrankheiten, H+G 3 (72) 161-5. 1997.

149. Karakousis CP, Balch CM, Urist MM, Smith TJ, Bartolucci AA. Local recurrence in malignant melanoma: longterm of the multi-institutional randomized surgical trial. Ann Surg Oncol. 1996; 3: 446-52.

150. Balch CM, Soong SJ, Bartoluicci AA, Urist MM, Karakousis CP, Smith TJ. Efficacy of an elective regional lymph node dissection of 1 to $4 \mathrm{~mm}$ thick melanoma for patients 60 years of age and younger. Ann Surg. 1996; 224: 255-66.

151. Balch CM, Soong SJ, Murad TM, Ingalls AL, Maddox WA. A multifactorial analysis of melanoma. III. Prognostic factors in melanoma patients with lymph nodes metastases (stage II). Ann Surg. 1981; 193: 377-88.

152. Balch CM, Soong SJ, Murad TM, Smith JW, Maddox WA, Durant JR. A multifactorial analysis of melanoma. IV. Prognostic factors in 200 melanoma patients with distant metastases (stage III). J Clin Oncol. 1983; 1: 126-34.

153. Kradin RL, Lazarus DS, Dubinett SM, Gifford J, Grove B, Kurnick JT et al. Tumour-infiltrating lymphocytes and interleukin-2 in treatment of advanced cancer. Lancet. 1989; 1: 577-88.

154. Balch CM, Buzaid AC, Atkins MB, Cascinelli N, Coit DG, Fleming ID et al. A New American Joint Committee on Cancer staging system for cutaneous melanoma. Cancer. 2000; 88: 1484-91.

155. Rigel DS, Friedman RJ, Kopf AW. The incidence of malignant melanoma in the United States: Issues as we approach the 21st century. J Am Acad Dermatol. 1996; 34: 839-47.

156. Parker SL, Tong TT, Bolden S et al. Cancer statistics, 1996. CA Cancer J Clin 1996; 46: 5-27.

157. Soong SJ et al. Predicting outcome in patients with localized melanoma. En Balch CM, Houghton AN, Sober AJ, Soong SJ. Cutaneous melanoma. St. Louis, Quality Medical. 1998: 51-61.

158. Balch et al. Efficacy of an elective regional lymph node dissection of 1 to $4 \mathrm{~mm}$ thick melanomas for patients 60 years of age and younger. Ann Surg. 1996; 224: p. 255.

159. Cascinelli $\mathrm{N}$ et al. Immediate or delayed dissection of regional nodes in patients with melanoma of the trunk: A randomized trial (WHO melanoma programme). Lancet. 1998; 351: p. 973.

160. Krag DN,Weaver DL, Alex JC et al. Surgical resection and radiolocalization of the sentinel lymph node in breast cancer using a gamma probe. Oncology. 1993; 2: 335-40. 
161. Alex JC, Weaver DL, Fairbank JT et al. Gamma probe guided lymph node localization in malignant melanoma. Surg Oncol. 1993; 2: 303-8.

162. Alex JC, Krag DN. Gamma probe guided localization of lymph nodes. Oncology. 1993; 2: 137-43.

163. Reintgen D, Cruse CW, Wells $\mathrm{K}$ et al. The orderly progression of melanoma nodal metastases. Am Surg. 1994; 220: 759-67.

164. Berger DH, Feig DW, Podoloff D. Lymphoscintigraphy as a predictor of lymphatic drainage from cutaneous melanoma. Ann Surg Oncol. 1997; 4: 247-51.

165. O'Brien CJ, Uren RF, Thompson JF et al. Prediction of potential metastatic sites in cutaneous head and neck melanoma using lymphoscintigraphy. Am J Surg. 1995; 170: 461-6.

166. Krasnow AZ, Hellman RS. Lymphoscintigraphy revisited: 1999. En Freeman LM. Nucl Med Ann 1999. Lippincott Williams \& Wilkins, Philadelphia. 1999: 17-97.

167. Kapteijn BAE, Nieweg O, Liem I et al. Localizing the sentinel node in cutaneous melanoma: Gamma probe detection versus blue dye. Ann Surg Oncol. 1997; 4: 156-60.

168. Alazraki NP, Eshima D, Herda SC et al. Lymphoscintigraphy, the sentinel node concept and the intraoperative gamma probe in melanoma, bresat cancer and other potential cancers. Sem Nucl Med. 1997; 27: 55-67.

169. Vidal-Sicart S, Piulachs J, Pons F et al. Detección del ganglio centinela mediante linfogammagrafía y sonda de rayos gamma intraoperatoria en pacientes con melanoma maligno. Resultados preliminares. Rev Esp Med Nucl. 1998; 17: 15-20.

170. Berman CG, Choi J, Hersh MR et al. Melanoma lymphoscintigraphy and lymphatic mapping. Sem Nucl Med. 2000; 30: 49-55.

171. Statiius MG, van Leeuwen PAM, Borgstein PJ et al. The sentinel node procedure in cutaneous melanoma: an overview of 6 years' experience. Eur J Nucl Med. 1999; 26: S20-S25.

172. Vidal-Sicart S, Piulachs J, Pons F. Detección del ganglio centinela mediante linfogammagrafía y sonda detectora intraoperatoria en pacientes con melanoma maligno. Med Clin (Barc). 1999; 112: 681-84.

173. Gershenwald JE, Thompson W, Mansfield PF et al. Multiinstitutional melanoma lymphatic mapping experience: The prognostic value of sentinel lymph node status in 612 stage I or II melanoma patients. J Clin Oncol. 1999; 17: 976-83.

174. Keshgtar MRS, Ell PJ. Sentinel lymph node detection and imaging. Eur J Nucl Med. 1999; 26: 57-67.

175. van Diest PJ, Peterse HL, Borgstein PJ et al. Pathological investigation of sentinel lymph nodes. Eur J Nucl Med. 1999; 26: S43-S49.
176. National Institutes of Health Consensus Development Panel on Early Melanom. Diagnosis and treatment of early melanoma. JAMA. 1992; 268: 1314-9.

177. Atkins MB, et al. A prospective randomized phase III trial of concurrent biochemotherapy (BCT) with cisplatin, vinblastine, dacarbazine (CVD), Il-2 and interferon alpha-2b (IFN) versus CVD alone in patients with metastatic melanoma (E3695): An ECOG-coordinated intergroup trial. Proc ASCO 2003; abstr. 2487.

178. Keilholz U, et al. Dacarbazine, cisplatin and IFN-alpha$2 \mathrm{~b}$ with or without IL-2 in advanced melanoma: Final analysis of EROTC randomized phase III trial 18951. Proc. ASCO 2003; abstr. 2848.

179. Del Vecchio M, et al. Multicenter phase III randomized trial of cisplatin, vindesine and dacarbazine (CVD) versus CVD plus subcutaneous (sc) interleukin-2 (IL-2) and iterferon-alpha-2b (IFN) in metastatic melanoma patients (pts). Proc. ASCO 2003: abstr. 2849.

180. Journal of Experimental Medicine. 1999; 190 (11): 166978.

181. Botella Estrada R, Sanmartin Jiménez O, Guillén Barona C. Terapia génica en el melanoma. Servicio de Dermatología. Instituto Valenciano de Oncología. Valencia.

182. Jaimovich L. El rincón del melanoma. Act. Terap. Dermatol. 1999; 22.

183. Jaimovich L. El rincón del melanoma. Act. Terap. Dermatol. 1998; 21.

184. González A, Ballesteros DO, Politi AJ, Abbruzzese M, Foster Fernández J, Flom R, Woscoff A. Pautas para el seguimiento del melanoma cutáneo estadio I - II. Dermatología Argentina. Vol 1, N 1. 1995.

185. Urist MM, Hynds Karnell L. The National Cancer Data Base. Report on melanoma. Cancer. 1994; 74: 782-8.

186. Romero JB, Stefanato CM, Kopf AW, Bart RS. Follow up recommendations for patients with stage I malignant melanoma. J Dermatol Surg Oncol. 1994; 20: 175-8.

187. Slingluff CR, Dodge RK, Stanley WE, Seigle HF. The annual risk of melanoma progression. Implications for the concept of cure. Cancer. 1992; 70: 1917-27.

188. Milton GW. Clinical features of secondary malignant melanoma. Australas J Dermatol. 1993; 34: 53-8.

189. Balch CL, Houghton AN. Diagnosis of metastatic melanoma at distant sites. En Balch CL, Houghton AN, Milton GW, Sober AJ, Soong S. Cutaneous Melanoma. 2nd Edit. Philadelphia. JB Lippincott Company. 1992; pp. 439-67.

190. Smith TJ, Kemeny MM, Sugarbaker PH, Jones AE, Vermes M, Shawker TH, Edwards BK. A prospective study of hepatic imaging in the detection of metastatic disease. Ann Surg. 1982; 195: 486-91. 
